\title{
Tailoring the shape of amorphous nanomaterials: recent developments and applications
}

\author{
Jianwei Nai, Jianxin Kang and Lin Guo*
}

\begin{abstract}
Nanoscale amorphous materials are very important member of the non-crystalline solids family and have emerged as a new category of advanced materials. However, morphological control of amorphous nanomaterials is very difficult because of the atomic isotropy of their internal structures. In this review, we introduce some emerging innovative methods to fabricate well-defined, regular-shaped amorphous nanomaterials. We then highlight some examples to evaluate the use of these amorphous materials in electrodes, and their optical response. There is still plenty of room to explore the amorphous world. As researchers continue to advance the scientific tools that underpin the concepts related to "amorphous", additional applications of these materials will emerge. Their controlled synthesis will undoubtedly attain new heights in the discipline of nanomaterials, and allow nanoscale amorphous materials to become more sophisticated, diverse, and mainstream.
\end{abstract}

\section{INTRODUCTION}

According to their atomic ordering and arrangement, solids can be divided into crystalline/quasicrystalline and amorphous. Compared with crystalline solids, amorphous ones do not possess long-range atomic order, but only short-range order over a few atoms. Amorphous materials (also called non-crystalline or vitreous materials) are common in the natural world and are familiar to us as a wide range of materials including rubber, glass, plastic and asphalt. Amorphous materials are characterized by the following four points: (i) long-range atomic disorder; (ii) isotropic physical and chemical properties; (iii) are metastable, but could undergo relaxation towards crystallinity with heat or pressure; (iv) without a specific melting point, but have a glass transition temperature [1]. In contrast, crystalline materials are only a particular state of condensed matter. Conventional characterization techniques for materials, such as powder X-ray diffraction (XRD), selected-area electron diffraction (SAED), and high-resolution transmission electron microscopy (HRTEM), can identify amorphous states but cannot analyze them. Spectroscopic measurements like X-ray photoelectron spectroscopy and $\mathrm{X}$-ray absorption spectroscopy are usually used to analyze amorphous structures. Unfortunately, at present we still know less about amorphous materials than crystalline ones from a scientific viewpoint. This is because the internal structure of amorphous materials is so complicated that almost no success has been achieved in building a complete model or systematic theory to represent or describe them. Nevertheless, the less explored amorphous materials are, the more fascinating they are to researchers. Some important findings related to the internal structure of metallic glass, e.g., short-range order [2,3], medium-range order $[4,5]$, polymorphism [6], and long-range topological order [7], have been reported recently. Effort has also been devoted to the study of local atomic environment [8,9] and lithium transport [10] in other kinds of amorphous materials. Furthermore, their specific atomic arrangement enables amorphous materials to exhibit high performance in mechanics and catalysis [11-14], as well as interesting magnetic properties [15-17]. However, the low specific surface area of bulk amorphous materials severely restricts their applications.

Nanoscale amorphous materials are important noncrystalline solids and are new type of advanced materials [18-30]. They have larger specific surface area than their bulk counterparts and therefore can show better performance and be applicable in more fields. For example, Ma and co-workers [22] examined submicron-sized metallic glass samples by an in situ transmission electron microscope (TEM) tensile deformation technique. They found that the elastic strain limit and corresponding strength of the submicron-sized samples were about twice those of the already impressive elastic limit of bulk metallic glass samples, approaching the ideal elastic limit of metallic glasses. Because they have smaller size and better transport properties than bulk amorphous materials, amorphous nanomaterials can also be used in transistor devices $[18,20]$ and lithium-ion batteries as electrode materials [25-27,30], while the bulk materials cannot.

The properties of nanomaterials strongly depend on their structure [31,32]. This "structure" can generally be divided into four categories: size [33,34], shape [35-38], 
composition [39,40] and assembly [41,42]. Therefore, tailoring these structural factors to tune the properties of nanomaterials is regarded as a challenge that must be overcome to realize applications in nanotechnology. However, structure tuning, especially morphological control of amorphous nanomaterials is very difficult. Because of their complex internal structure, the growth of amorphous nanomaterial is usually ruleless, resulting in irregular particles using solution approaches or thin films using deposition techniques as their conventional shape. Over the last decade, inorganic amorphous nanomaterials with a variety of novel shapes, with notable examples including spheres, wires, tubes, fibers, cubes, octahedra, polyhedra, flower-like spheres and arrays, which are summarized in

Table 1 Different shapes of amorphous nanomaterials with various compositions synthesized by different methods

\begin{tabular}{|c|c|c|c|c|}
\hline Category & Product shape & Composition & Method & Ref. \\
\hline \multirow{17}{*}{$\begin{array}{l}\text { Spheres } \\
\text { (0D) }\end{array}$} & spheres (hollow) & $\mathrm{CaCO}_{3}$ & gas-diffusion solution method & {$[43]$} \\
\hline & spheres & $\mathrm{CaCO}_{3}$ & solution method & {$[44]$} \\
\hline & spheres & $\mathrm{CaCO}_{3}$ & solution method & {$[45]$} \\
\hline & spheres & $\mathrm{CaCO}_{3}$ & solution method & {$[46]$} \\
\hline & spheres & $\mathrm{CaCO}_{3}$ & solution method & {$[47]$} \\
\hline & spheres & $\mathrm{Si}$ & thermal decomposition & {$[48]$} \\
\hline & spheres & $\mathrm{Si}$ & solution method & {$[49]$} \\
\hline & spheres & $\mathrm{Si} / \mathrm{Ti}$ & solution method & {$[50]$} \\
\hline & spheres & $\mathrm{Si}: \mathrm{H}$ & thermal decomposition & {$[51]$} \\
\hline & spheres & $\mathrm{Si}: \mathrm{H}$ & thermal decomposition & {$[52]$} \\
\hline & spheres & $\mathrm{Se}$ & solution method & {$[53]$} \\
\hline & spheres & $\mathrm{TiO}_{2}$ & solution method & {$[54-56]$} \\
\hline & spheres (hollow) & $\mathrm{PbO}-\mathrm{TiO}_{2}$ & sol-gel method & {$[57]$} \\
\hline & spheres & Co-B alloy & solution method & {$[58]$} \\
\hline & spheres & $\mathrm{Fe}_{x} \mathrm{Ni}_{y} \mathrm{O}_{z}$ & aerosol-spray method & {$[59]$} \\
\hline & spheres & $\mathrm{FePO}_{4}$ & solution method & {$[60]$} \\
\hline & spheres & zinc citrate & solution method & {$[61]$} \\
\hline \multirow{6}{*}{$1 \mathrm{D}$} & nanotubes & carbon & solution method & {$[62]$} \\
\hline & nanofibers & $\mathrm{Zn}_{2} \mathrm{SnO}_{4}$ & electrospinning & {$[63]$} \\
\hline & nanowires (NWs) & $\mathrm{SiO}_{x} \mathrm{~N}_{y}$ & thermal treat growth & {$[64]$} \\
\hline & NWs & $\mathrm{SiO}_{x}$ & laser vapor deposition & {$[65]$} \\
\hline & NWs (shell of a core/shell structure) & $\mathrm{Si}$ & chemical vapor deposition (CVD) & {$[66]$} \\
\hline & NWs (shell of the core/shell structure) & $\mathrm{Si}$ & plasma-enhanced CVD & {$[67]$} \\
\hline \multirow{2}{*}{$2 \mathrm{D}$} & nanosheets & $\mathrm{H}_{2} \mathrm{Ti}_{2} \mathrm{O}_{5}$ & solid-state annealing & {$[68]$} \\
\hline & nanosheets & $\mathrm{FeOOH}$ & surfactant-assisted oxidation & [69] \\
\hline \multirow{6}{*}{$3 \mathrm{D}$} & nanocolumn arrays & $\mathrm{TiO}_{2}$ & pulsed-laser deposition & [70] \\
\hline & nanotube arrays & $\mathrm{TiO}_{2}$ & electrochemical oxidation & {$[71]$} \\
\hline & nanotube arrays & $\mathrm{TiO}_{2}$ & electrochemical oxidation & {$[72]$} \\
\hline & nanowire and nanocone arrays & $\mathrm{Si}: \mathrm{H}$ & reactive ion etching & {$[73]$} \\
\hline & microlens arrays & $\mathrm{CaCO}_{3}$ & solution method & [74] \\
\hline & $\begin{array}{c}\text { nanoneedle arrays } \\
\text { (shell of a core/shell structure) }\end{array}$ & $\mathrm{Ge}$ & CVD & {$[75]$} \\
\hline \multirow{9}{*}{$\begin{array}{c}\text { Unique } \\
\text { shapes } \\
(0 D)\end{array}$} & flower-like nanospheres & $\mathrm{Ni}(\mathrm{OH})_{2}$ & electrochemical deposition & {$[76]$} \\
\hline & flower-like nanospheres & $\mathrm{Ni}(\mathrm{OH})_{2}$ & electrochemical deposition & {$[77]$} \\
\hline & flower-like nanospheres & $\mathrm{Co}(\mathrm{OH})_{2}$ & electrochemical deposition & {$[78]$} \\
\hline & nanoboxes & $\mathrm{CoSnO}_{3} @ \mathrm{C}$ & solution method and annealing & [79] \\
\hline & nanocages (octahedral) & $\begin{array}{c}\mathrm{Mn}(\mathrm{OH})_{2} / \mathrm{MnO}(\mathrm{OH}), \mathrm{Fe}(\mathrm{OH})_{3} \\
\mathrm{Co}(\mathrm{OH})_{2}, \mathrm{Ni}(\mathrm{OH})_{2}, \mathrm{Zn}(\mathrm{OH})_{2}, \mathrm{~Pb}(\mathrm{OH})_{2}\end{array}$ & solution method & {$[80]$} \\
\hline & nanoboxes & $\mathrm{Ni}(\mathrm{OH})_{2}$ & solution method & {$[81]$} \\
\hline & nanocubes (hollow) & $\mathrm{Co}(\mathrm{OH})_{2}$ & solution method & {$[82]$} \\
\hline & nanopolyhedra (hollow) & $\mathrm{CoS}$ & solution method & {$[83]$} \\
\hline & mesopores nanocubes & $\mathrm{ZnSnO}_{3}$ & solution method and annealing & {$[84]$} \\
\hline
\end{tabular}


Table 1, have been synthesized. In this review, we explain how these exquisite nanostructures can be obtained by a number of innovative methods. Next, we highlight some examples to demonstrate how these amorphous materials can be used as electrode materials, and discuss their optical response. Finally, we summarize the approaches that can be used to tailor the shape of amorphous nanomaterials. We focus on the scientific challenges currently and may face in the study of the preparation, formation mechanism, internal structure, and potential applications of amorphous nanomaterials.

\section{MORPHOLOGIES OF AMORPHOUS NANOMATERIALS}

\section{Spheres}

Spheres are highly symmetric and thus often regarded as beautiful. "Spherical" can also be understood as "isotropic" from a scientific viewpoint. This indicates that tuning the morphology of amorphous nanomaterials to obtain spheres is not difficult because it is promoted by the intrinsic isotropic nature of amorphous materials. Spherical structure is also favorable in terms of surface energy. Nanospheres are the most reported shape of amorphous materials in the last decade (see Table 1), and they can be composed of calcium carbonate $\left(\mathrm{CaCO}_{3}\right)$ [43-47], silicon ( $\left.\mathrm{Si}\right)$ [48-52], metals or their compounds [53-61].

$\mathrm{CaCO}_{3}$ is abundant in the natural world, and a typical model system used to mimic the mineralization process of biominerals [43]. A facile method to prepare $\mathrm{CaCO}_{3}$ is to mix aqueous solutions of calcium chloride and sodium carbonate to form metastable amorphous calcium carbonate (ACC) initially, which then transforms to crystalline $\mathrm{CaCO}_{3}$ within a few minutes in solution. This rapid process makes it difficult to study the properties of ACC and the mechanism of the mineralization process. Some specific additives, such as organic macromolecules and magnesium ions, have been used to stabilize ACC nanospheres by forming complexes with metal ions $[44,46,47]$. Huang et al. [47] reported a poly(acrylic acid) (PAA)-assisted method to synthesize highly stable, size-controlled monodisperse ACC nanospheres. They suggested that the amorphous state was induced and stabilized more with higher atomic structure disorder using a shorter complexation time as well as PAA with an medium molar mass rather than PAA with lower or higher molar mass. This is because a variety of intermediates of the PAA- $\mathrm{Ca}^{2+}-\mathrm{H}_{2} \mathrm{O}$ complex coexist in the earlier stage of complexation; that is, the coordination of $\mathrm{Ca}^{2+}$ ions with PAA is more random earlier in the reaction. Phytic acid is another effective inhibitor of the crystallization of ACC nanospheres fabricated using a gas-diffusion method, as described by Xu et al. [43]. They also found that hydrated ACC can form on the exterior of anhydrous ACC and then grow at the expense of the dissolving internal anhydrous ACC particles, producing a hollow nanostructure.

Layers of amorphous silicon ( $\mathrm{a}-\mathrm{Si}$ ) are useful in various fields and are usually vapor-deposited on substrates [52], which confines their use to applications that require the availability of large quantities of particles, like fuel cells. Nanospheres of a-Si have high surface area-to-volume ratios and bond hydrogen more strongly than bulk a-Si. A general approach to fabricate a-Si nanospheres is decomposition of trisilane in organic solvent $[48,51,52]$. In Korgel's report [52], spherical hydrogenated amorphous silicon (a-Si:H) colloids were synthesized by decomposition of trisilane in supercritical hexane. The a-Si:H colloids exhibited fairly wide ranges of size, hydrogen content, and Si bond order, depending on the synthesis temperature, pressure, and reactant concentration. Scanning electron microscope (SEM) images of the a-Si nanospheres are presented in Fig. 1. Raman results suggested the a-Si nanospheres with least structural order yielded using the lowest reaction temperature would load most hydrogen.

Apart from the common amorphous nanospheres composed of $\mathrm{CaCO}_{3}$ and $\mathrm{Si}$, and amorphous nanospheres of some other compounds, such as $\mathrm{Se}$ [53], $\mathrm{TiO}_{2}$ [54-57], Co-B alloy [58], $\mathrm{FePO}_{4}$ [60] and zinc citrate [61], have also been prepared, generally by facile solution routes. Recently, Kuai et al. [59] reported an interesting aerosol-spray-as-

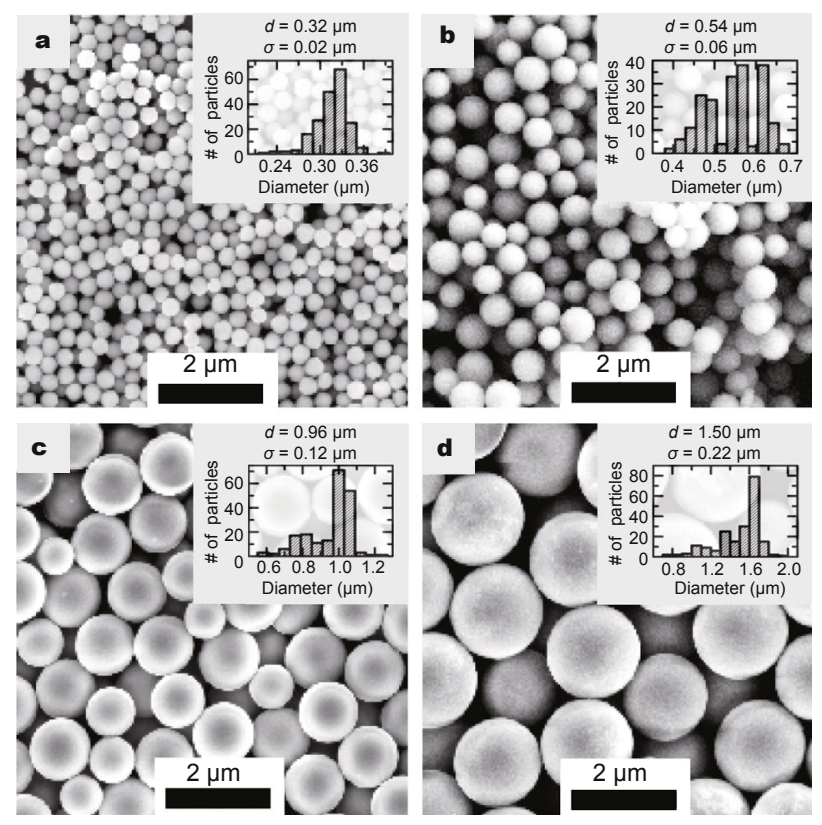

Figure 1 SEM images of a-Si:H particles synthesized in supercritical hexane at $420^{\circ} \mathrm{C}$ and $34.5 \mathrm{MPa}(5000 \mathrm{psi})$ with different amounts of trisilane: (a) 20, (b) 60, (c) 100 and (d) $300 \mu \mathrm{L}$. Inset are particle size distributions determined from SEM images. Reprinted with permission from Ref. [52]. Copyright 2010, American Chemical Society. 
sisted approach (ASAA) combined with evaporation-induced self-assembly (EISA) as a precisely controllable and continuous method to prepare mixed-metal oxide amorphous microspheres, as illustrated in Fig. 2. Taking Fe$\mathrm{Ni}$ oxides as an example, precursor solutions containing Pluronic P123, $\mathrm{Fe}\left(\mathrm{NO}_{3}\right)_{3}$ and/or $\mathrm{Ni}\left(\mathrm{NO}_{3}\right)_{2}$ salts were first sprayed into droplets by an ultrasonic humidifier. The mist (the right-hand side, Fig. 2a) was then driven into a tube furnace by a pump and preheated to $480^{\circ} \mathrm{C}$. During this process, inorganic precursors solidified, decomposed into metal oxides, and then assembled to form microspheres with the assistance of P123 (the left-hand side, Fig. 2a). Because of the short reaction time (several seconds), the metal oxides did not have sufficient time to crystallize and the final products were therefore amorphous. Fig. 2b suggests the metal elements that could be used in this method to fabricate amorphous oxide nanospheres with single or multiple components. Importantly, they also claimed that the ASAA was suitable for large-scale industrial production because the product can be successively obtained at a rate of about $0.1 \mathrm{~g} \mathrm{~h}^{-1}$.

\section{Nanotubes, nanowires, and nanofibers}

One-dimensional (1D) nanomaterials have attracted considerable research interest because of their numerous applications including gas sensors, nanoelectronics, and energy storage [85-88]. The long-range disorder of amorphous materials generally makes them unable to form $1 \mathrm{D}$ nanostructures, which have obvious anisotropy, without any attached host [62] or particular guiding technique [63-67]. Nanotubes, NWs, and nanofibers are three typical types of $1 \mathrm{D}$ nanomaterials. Zhu's group [62] synthesized amorphous carbon nanotubes (a-CNTs), an important porous carbon nanostructure, on a large scale from a self-seeded solution-base reaction. Each a-CNT was 3-5 $\mu \mathrm{m}$ in length and $\sim 300 / 200 \mathrm{~nm}$ in (outer/inner) diameter, and had a Brunauer-Emmett-Teller (BET) specific surface area of $431 \mathrm{~m}^{2} \mathrm{~g}^{-1}$ with a narrow pore distribution of about 4.03 $\mathrm{nm}$. The time-dependent morphology evolution of the nanotubes was examined to investigate their growth mechanism. They found that a bunch of short nanotubes with closed ends can develop from the tips at the surface of the initially generated carbon microparticles. Over time, these

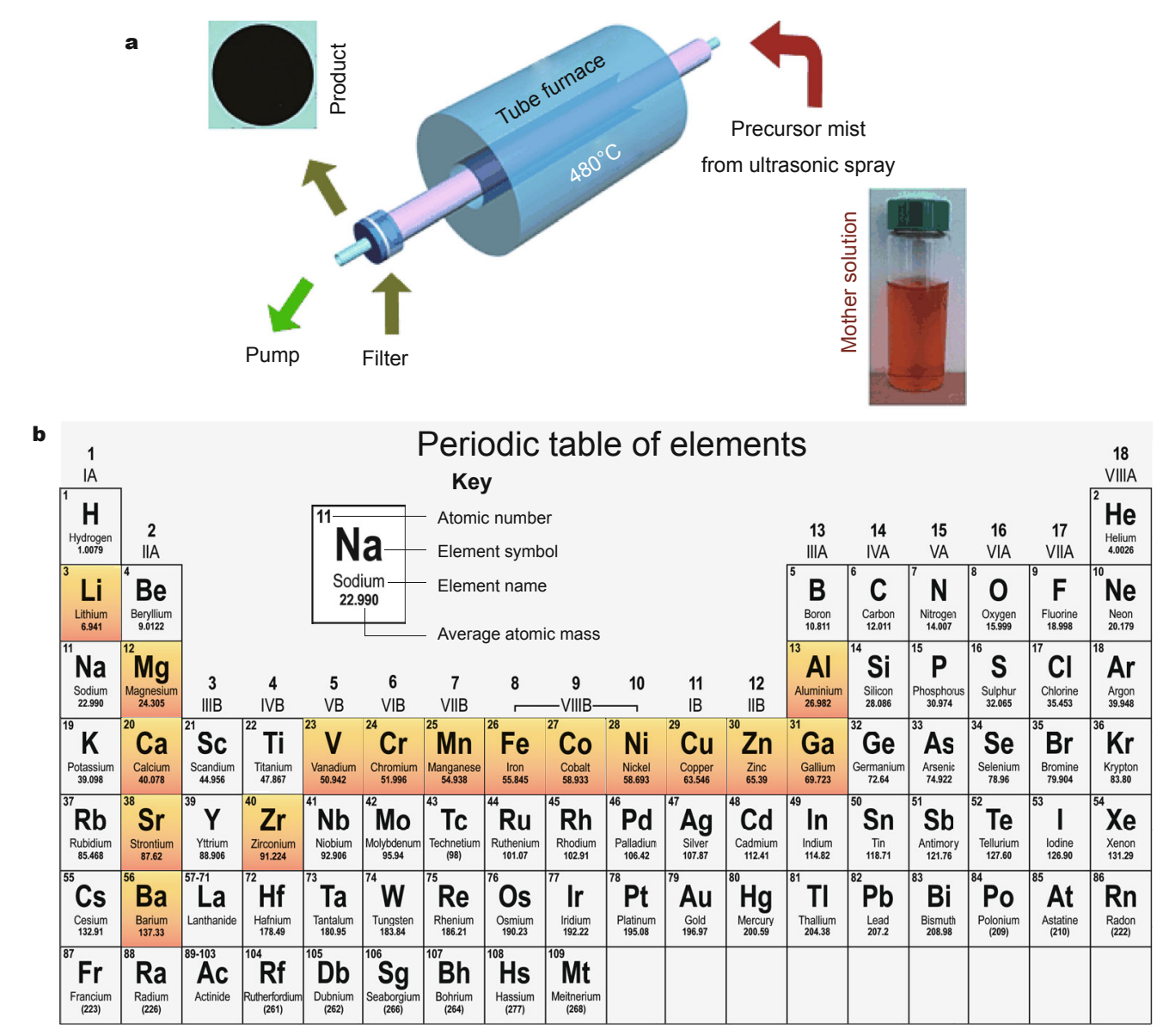

Figure 2 (a) Illustration of the setup to fabricate amorphous metal oxide microspheres by the ASAA; (b) possible amorphous metal oxides that could be obtained using the ASAA with inorganic salts. Adapted with permission from Ref. [59]. Copyright 2014, Wiley-VCH Publishers, Inc. 
CNTs elongate, keeping their diameter and wall thickness almost unchanged. This process is similar to the laser vaporization-assisted approach used to grow amorphous $\mathrm{SiO}_{x}$ NWs [65].

Amorphous NWs can also be prepared by the ways of CVD and plasma techniques $[64,66,67]$. For example, Zheng et al. [64] demonstrated that the combination of $\mathrm{Ni}$-catalyzed transformation with $\mathrm{NH}_{3}$ plasma could be an effective and facile method to form amorphous silicon oxynitride, as shown in Fig. 3. They claimed that both the nitrogen species and active hydrogen generated in the $\mathrm{NH}_{3}$ plasma were required for NW formation: the former ensured the incorporations of nitrogen, while the latter maintained the activity of the catalyst. The catalytic function of Ni nanoparticles (NPs) and a sufficient amount of reactive species are also important in the growth of NWs.

Fiber-like $\mathrm{Zn}_{2} \mathrm{SnO}_{4}$ amorphous structures have been fabricated by an electrospinning method [63]. Figs $4 a-d$ show the microstructures of $\mathrm{Zn}_{2} \mathrm{SnO}_{4}$ fibers obtained after heating from 450 to $700^{\circ} \mathrm{C}$. Well-interconnected fused $\mathrm{Zn}$ Sn precursor/poly(vinyl acetate) (PVAc) composite fibers are depicted in Fig. 4e. Subsequent calcination at $450^{\circ} \mathrm{C}$ for $1 \mathrm{~h}$ in air resulted in a highly porous network structure (see Fig. 4f) with a high specific surface area of $124 \mathrm{~m}^{2} \mathrm{~g}^{-1}$. The inset image in Fig. 4f suggests that the $\mathrm{Zn}_{2} \mathrm{SnO}_{4}$ fibers are composed of NPs with a diameter of less than $5 \mathrm{~nm}$. Figs $4 \mathrm{~h}$ and $\mathrm{i}$ indicate that the surface of the fibers is relatively smooth and porous. The inset image in Fig. 4 j shows that the fibers exhibited a ring diffraction pattern consistent with amorphous structure. An HRTEM image of the fibers (Fig. 4j) does not contain a crystalline lattice fringe, con-

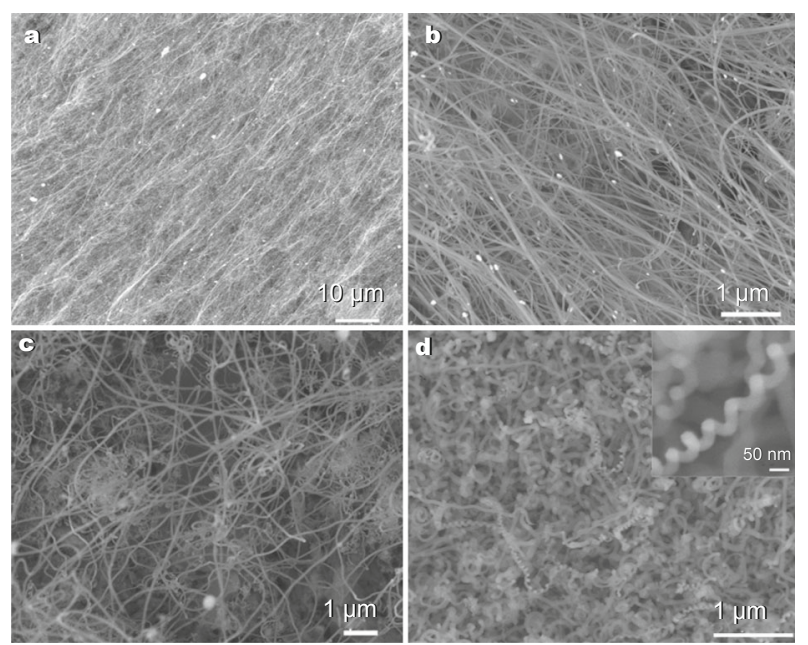

Figure 3 SEM images of NWs grown by plasma treatment in (a) and (b) $\mathrm{NH}_{3} / \mathrm{Ar}=5 / 50$, (c) $\mathrm{NH}_{3} / \mathrm{Ar}=1 / 50$, and (d) by thermal treatment in $\mathrm{NH}_{3} / \mathrm{Ar}=1 / 50$. The inset shows a magnified image of a helical NW. The Ni film thickness was $20 \mathrm{~nm}$. Reprinted with permission from Ref. [64]. Copyright 2008, American Chemical Society.

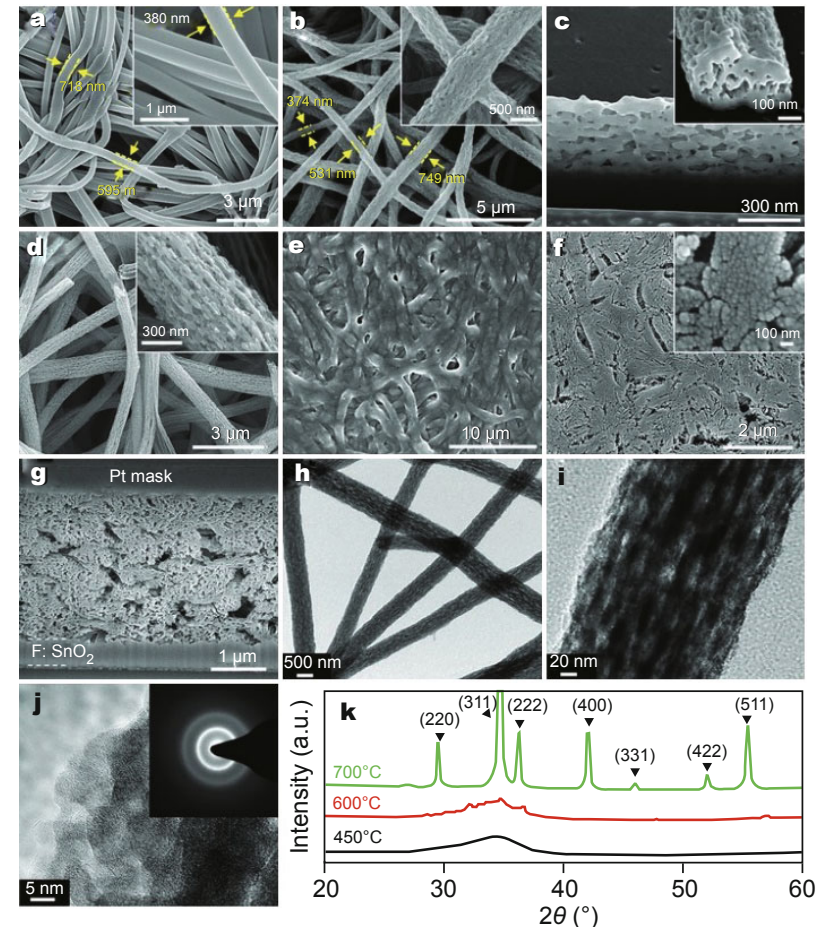

Figure 4 SEM images of (a) as-spun $\mathrm{Zn}(\mathrm{OAc})_{2}-\mathrm{Sn}(\mathrm{OAc})_{4} / \mathrm{PVAc}$ composite fibers, (b) $\mathrm{Zn}_{2} \mathrm{SnO}_{4}$ fibers calcined at $500^{\circ} \mathrm{C}$, (c) cross-sectional view of $\mathrm{Zn}_{2} \mathrm{SnO}_{4}$ fibers calcined at $500^{\circ} \mathrm{C}$, (d) $\mathrm{Zn}_{2} \mathrm{SnO}_{4}$ fibers calcined at $700^{\circ} \mathrm{C}$, (e) hot-pressed $\mathrm{Zn}(\mathrm{OAc})_{2}-\mathrm{Sn}(\mathrm{OAc})_{4} / \mathrm{PVAc}$ composite fibers, (f) $\mathrm{Zn}_{2} \mathrm{SnO}_{4}$ fibers calcined at $450^{\circ} \mathrm{C}$ after hot pressing, (g) cross-sectional view of $\mathrm{Zn}_{2} \mathrm{SnO}_{4}$ fibers calcined at $450^{\circ} \mathrm{C}$ after hot pressing, (h) TEM image of $\mathrm{Zn}_{2} \mathrm{SnO}_{4}$ fibers calcined at $450^{\circ} \mathrm{C}$ after hot pressing, (i) magnified view of the TEM image in (h), (j) magnified view of the TEM image in (i) and the inset shows a SAED pattern, and (k) XRD pattern of $\mathrm{Zn}_{2} \mathrm{SnO}_{4}$ fibers calcined at temperatures of 450,600 , and $700^{\circ} \mathrm{C}$. Reprinted with permission from Ref. [63]. Copyright 2013, Wiley-VCH Publishers, Inc.

firming the fibers are amorphous, as in their XRD pattern (Fig. 4k).

\section{Nanosheets}

The large surface area of two-dimensional (2D) nanomaterials, including sheets and plates, makes them promising for applications in electrochemical and optical fields $[89,90]$. However, few 2D amorphous nanomaterials have been reported $[68,69]$, which might be because of their limited synthetic methodology.

$\mathrm{Xu}$ et al. [69] presented a facile approach to synthesize amorphous iron oxyhydroxide nanosheets by the surfactant-assisted oxidation of iron sulfide nanosheet. An SEM image (Fig. 5a) and low-magnification TEM image (Fig. $5 b)$ of the product reveal its loose, corrugated graphenelike 2D nanosheet structure. An HRTEM image of an individual nanosheet (Fig. 5c) shows that it consists of NPs aggregated to form a porous structure. The diameters of these NPs are less than $5 \mathrm{~nm}$. Another HRTEM image (Fig. 

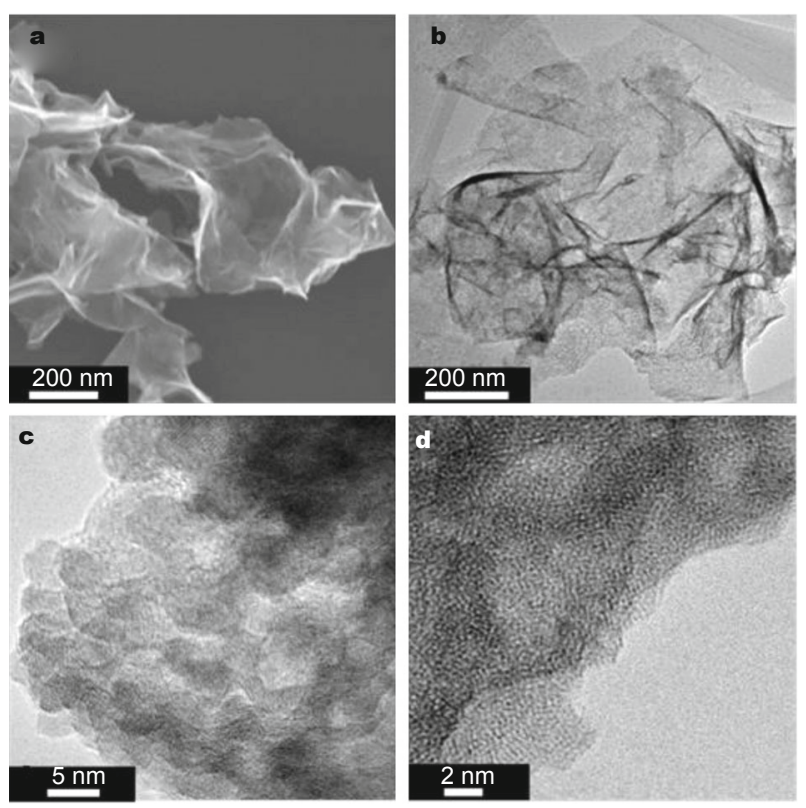

Figure 5 (a) SEM image, (b) TEM image, and (c, d) HRTEM images of an amorphous iron oxyhydroxide nanosheet. Reprinted with permission from Ref. [69]. Copyright 2013, American Chemical Society.

$5 d)$ suggests that the atomic lattice on the surface of the nanosheets lacked regular periodicity, which further confirms the amorphous nature of the nanosheets. The BET surface area of the porous nanosheets determined by nitrogen absorption/desorption measurements is $233 \mathrm{~m}^{2} \mathrm{~g}^{-1}$.

\section{Arrays}

Fabricating three-dimensional (3D) ordered arrays is a goal of researchers because these arrays can show enhanced performance over an individual unit [91]. Some pioneering methods have been demonstrated that can be used to construct arrays based on amorphous nanomaterials, such as pulsed laser deposition (PLD) [70], electrochemical oxidation [71,72], reactive ion etching (RIE) [73], solution-based self-assembly [74] and CVD [75].

Li et al. [70] fabricated a hexagonal-close-packed (hcp), hierarchical amorphous $\mathrm{TiO}_{2}$ nanocolumn array by PLD using a polystyrene (PS) colloidal monolayer as a template. A top-view SEM image of the array (Fig. 6a) reveals an obvious hcp arrangement. Each nanocolumn is composed of a PS sphere at the bottom with a vertical nanocolumn on top, as shown in Fig. $6 \mathrm{~b}$. The nanocolumns and PS spheres have almost the same diameter, and the height of each column is about $870 \mathrm{~nm}$. The surface of each nanocolumn is very rough and high-resolution images of their sides show that they are composed of many nanobranches (Figs $6 \mathrm{c}$ and d). The formation of nanocolumns is caused by the shadow effect during the deposition between neighboring PS spheres: if one sphere in the template monolayer is com-
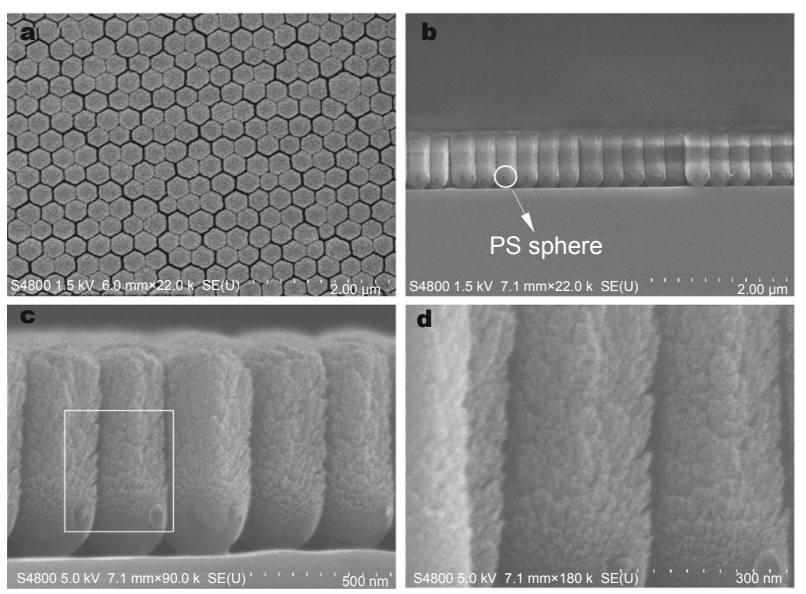

Figure 6 SEM images of a sample obtained by PLD using a PS colloidal monolayer as the substrate (PS sphere size: $350 \mathrm{~nm}$; deposition time: 70 min). (a) and (b) are low-magnification images observed from the top and side, respectively; (c) and (d) are high-resolution images observed from the side; (d) is a magnified image of (c). Reprinted with permission from Ref. [70]. Copyright 2008, American Chemical Society.

pletely surrounded by six other spheres, as in the case of hcp alignment, a nanocolumn will form on the top rather than the sides of this sphere. Thus an hcp nanocolumn array can be fabricated using a monolayer of colloidal PS spheres as a template.

A process to fabricate a-Si:H nanostructures is illustrated in Fig. 7 [73]. A $1 \mu$ m-thick a-Si:H film (Fig. 7a) was prepared by hot-wire CVD on an indium-tin-oxide (ITO)-coated glass substrate. The researchers used the Langmuir-Blodgett technique to assemble silica NPs into a close-packed monolayer on top of the a-Si:H thin film. These silica NPs (Fig. 7b) were then used as an etch mask during a chlorine-based RIE process, because the etching rate of silica was much lower than that of a-Si:H. NW (Fig. 7c) and nanocone (NC) (Fig. 7d) arrays can be fabricated using different RIE conditions. Figs $8 \mathrm{a}$ and $\mathrm{b}$ show SEM images of the silica NPs with a uniform size of $\sim 500 \mathrm{~nm}$ assembled as a close-packed monolayer on a-Si:H thin film. The a-Si:H NW arrays after RIE are depicted in Figs $8 \mathrm{e}$ and f. The length and diameter of each NW were $\sim 600$ and $\sim 300 \mathrm{~nm}$, respectively. The silica NPs can still be clearly seen on the top of each NW. Figs $8 \mathrm{c}$ and d present SEM im-

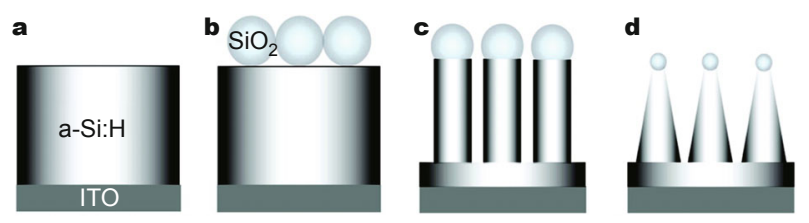

Figure 7 (a)-(d) Schematic illustrations of $1 \mu \mathrm{m}$-thick a-Si:H on an ITOcoated glass substrate with a monolayer of silica NPs on top of a-Si:H thin film, NW array, and NC array. Reprinted with permission from Ref. [73]. Copyright 2009, American Chemical Society. 

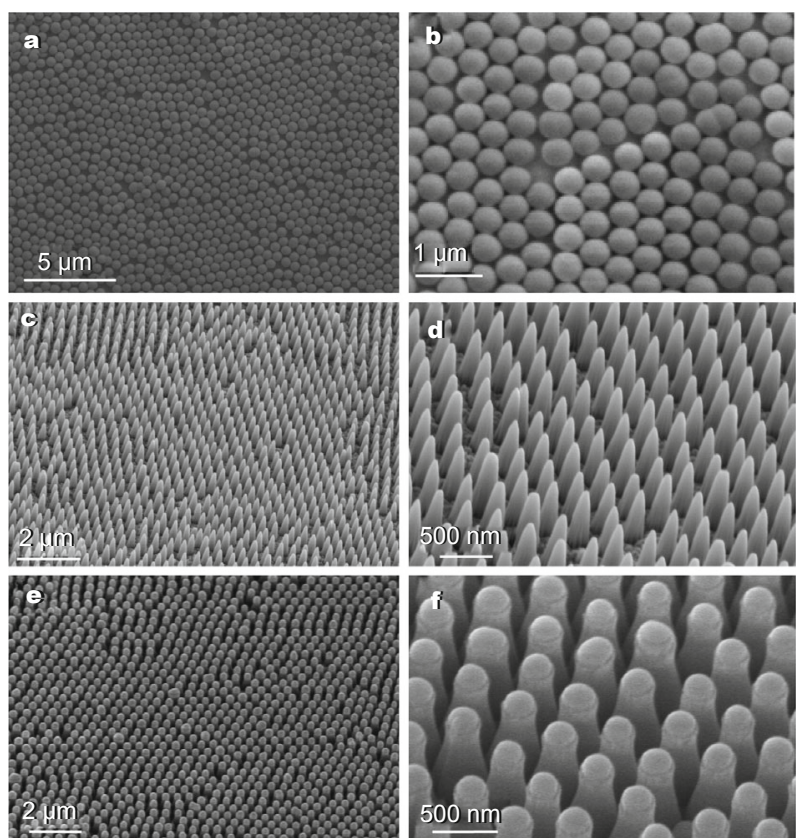

Figure 8 (a), (c) and (e) SEM images in a large area of a monolayer of silica NPs, a-Si:H NC arrays, and a-Si:H NW arrays, respectively; (b), (d) and (f) magnified SEM images of silica NPs, a-Si:H NCs, and a-Si:H NWs, respectively. Reprinted with permission from Ref. [73]. Copyright 2009, American Chemical Society.

ages of a-Si:H NC arrays, where each NC is $\sim 600 \mathrm{~nm}$ long. The tip diameter of these NCs is $\sim 20 \mathrm{~nm}$, while their base diameter is $\sim 300 \mathrm{~nm}$. It is believed that the conical shape of the NCs is caused by the gradual shrinkage of the silica NPs. After RIE, the silica NPs were so small that they are no longer observable on the top of the NCs.

\section{Other unique shapes}

Polyhedra with high anisotropy are a common nanocrystal morphology, and have been widely synthesized during the past decade $[92,93]$. Because of their long-range atomic order and arrangement, facet control in nanocrystals can be realized. In this regard, it seems very difficult for amorphous nanomaterials to present as polyhedra. Nevertheless, a small number of notable examples demonstrate the very recent progress in the fabrication of polyhedral amorphous nanostructures by some innovative methods [79-84].

Inspired by Pearson's hard/soft acid/base (HSAB) principle, our group explored a general strategy to fabricate uniform polyhedral amorphous nanocages of metal hydroxides (MHs) [80], which is outlined in Fig. 9. $\mathrm{Cu}_{2} \mathrm{O}$ nanocrystals were first prepared and used as a sacrificial template. We employed $\mathrm{Na}_{2} \mathrm{~S}_{2} \mathrm{O}_{3}$ as the coordinating etchant. $\mathrm{S}_{2} \mathrm{O}_{3}^{2-}$, which dissociated from $\mathrm{Na}_{2} \mathrm{~S}_{2} \mathrm{O}_{3}$, was a typical soft base in terms of the HSAB principle, while $\mathrm{Cu}^{+}$within the $\mathrm{Cu}_{2} \mathrm{O}$ template acted as a soft acid. $\left[\mathrm{Cu}_{2}\left(\mathrm{~S}_{2} \mathrm{O}_{3}\right)_{x}\right]^{2-2 x}$, as a more stable and soluble complex ion, forms as a re-

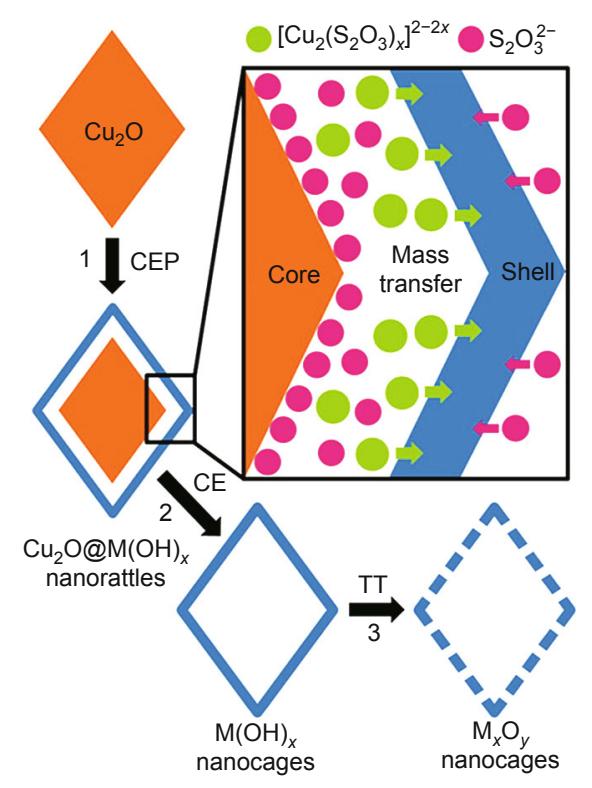

Figure 9 Schematic illustration of the fabrication of $\mathrm{M}(\mathrm{OH})_{x}(\mathrm{M}=\mathrm{Mn}$, $\mathrm{Fe}, \mathrm{Co}, \mathrm{Ni}, \mathrm{Zn}$ ) nanocages by synchronous coordinating etching of $\mathrm{Cu}_{2} \mathrm{O}$ nanocrystals, and the fabrication of $\mathrm{M}_{x} \mathrm{O}_{y}$ by thermal treatment of relevant $\mathrm{M}(\mathrm{OH})_{x}$. Abbreviations: CEP, coordinating etching and precipitating; CE, coordinating etching; TT, thermal treatment. Reprinted with permission from Ref. [80]. Copyright 2013, American Chemical Society.

sult of the interaction between $\mathrm{Na}_{2} \mathrm{~S}_{2} \mathrm{O}_{3}$ and $\mathrm{Cu}_{2} \mathrm{O}$ at the expense of $\mathrm{Cu}_{2} \mathrm{O}$. The exhaustion of $\mathrm{OH}^{-}$in the formation of $\mathrm{M}(\mathrm{OH})_{2}$ provides a strong driving force for further dissolution of $\mathrm{Cu}_{2} \mathrm{O}$ and hydrolysis of $\mathrm{S}_{2} \mathrm{O}_{3}{ }^{2-}$. As a result, when the etching process occurs, $\mathrm{M}(\mathrm{OH})_{2}$ starts precipitating synchronously and a shell structure forms preferentially around the etching interface where the local concentration of $\mathrm{OH}^{-}$is the highest.

The above process is defined as "coordinating etching and precipitating", which is shown as step 1 in Fig. 9. We believe that these two synchronous chemical reactions guarantee that the exterior $\mathrm{M}(\mathrm{OH})_{2}$ shell perfectly imitates the geometry of the $\mathrm{Cu}_{2} \mathrm{O}$ template. The shell structure can be preserved in the following coordinating etching procedure (step 2), even though in some cases (using $\mathrm{Mn}$ and $\mathrm{Fe}$ ) $\mathrm{M}(\mathrm{OH})_{2}$ might be oxidized to $\mathrm{M}(\mathrm{OH})_{x}$. The strong affinity between the etchant and template makes fabrication at low temperature possible. In addition, the reaction is completed rapidly without requiring any additional oxidizing or acid agents. The as-prepared $\mathrm{MH}$ amorphous nanocages are ideal precursor to synthesize metal oxide polycrystalline nanocages by conventional thermal treatment, which is illustrated as step 3 in Fig. 9.

This unique route shows potential to produce well-defined, high-quality $\mathrm{MH}$ nanocages with various components including manganese hydroxide, iron hydroxide, cobalt hydroxide, nickel hydroxide, zinc hydroxide (as shown 
in Fig. 10) and lead hydroxide. Figs $10 x_{1}(x=\mathrm{a}-\mathrm{e})$ reveal the $\mathrm{MH}$ nanocages have an octahedral structure with an edge length of $\sim 500 \mathrm{~nm}$, so they inherit the geometry and dimensions of the $\mathrm{Cu}_{2} \mathrm{O}$ template well. Figs $10 x_{2}$ show that the shell structure is composed of small particles. The inner cavity is clearly revealed by the contrast between the shells and hollow interiors (Figs $10 x_{3}$ ). The highly symmetric octahedral shell framework can be observed more distinctly in these perspective views. The shell of the nanocages is as thin as $\sim 40 \mathrm{~nm}$. The SAED patterns in Figs $10 x_{4}$ also suggest that the $\mathrm{MH}$ nanocages are amorphous.
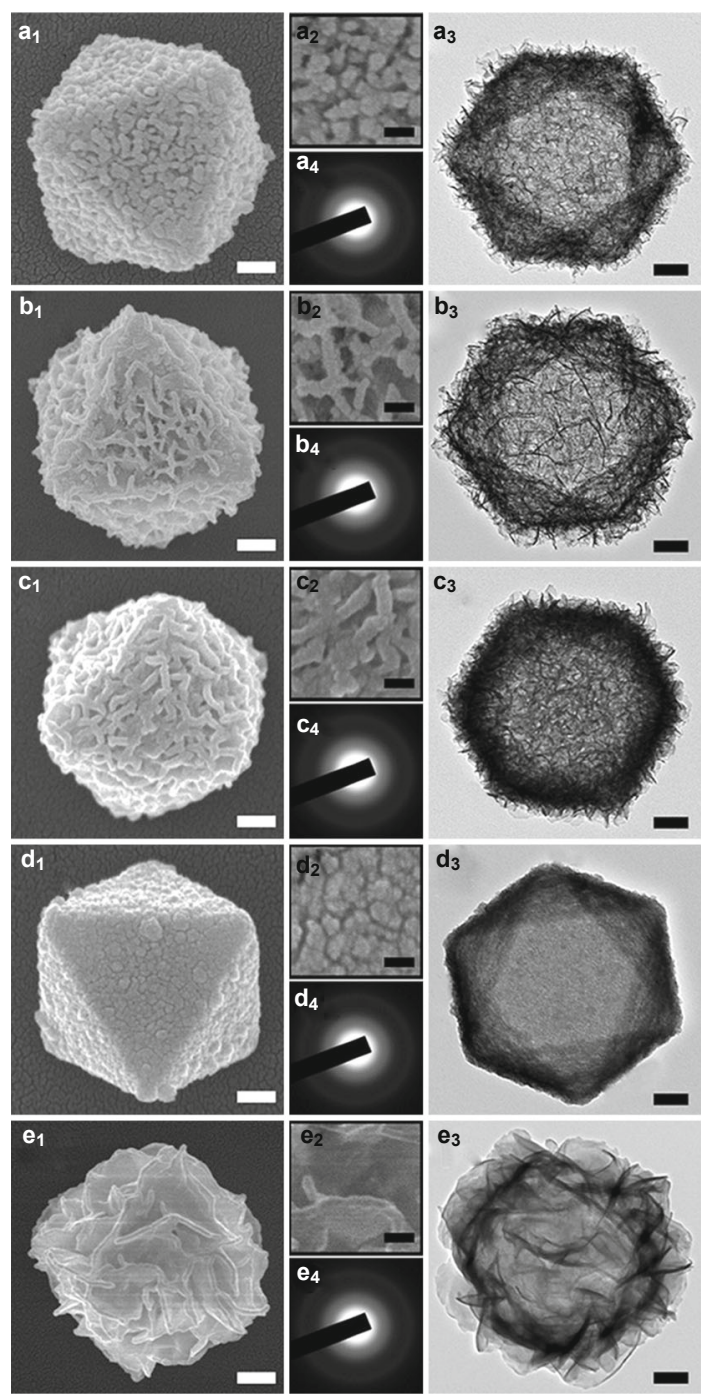

Figure 10 SEM, TEM, and SAED images of the (a) manganese, (b) iron, (c) cobalt, (d) nickel, and (e) zinc hydroxide nanocages. Parts $x_{1}$ $(x=\mathrm{a}-\mathrm{e})$ and $x_{3}$ show typical SEM and TEM images of MH nanocages, respectively; part $x_{2}$ shows high-magnification images of the surface of the corresponding cage in part $x_{1}$; part $x_{4}$ is the SAED patterns obtained for the whole cages in part $x_{3}$. The scale bars in parts $x_{1}, x_{2}$, and $x_{3}$ are 100, 20, and $100 \mathrm{~nm}$, respectively. Reprinted with permission from Ref. [80]. Copyright 2013, American Chemical Society.
We also used this strategy to fabricate amorphous nickel hydroxide $\left(\mathrm{Ni}(\mathrm{OH})_{2}\right)$ nanocages of different size [80], shell thickness [80] and shape (spheres and boxes) [80,81]. Hollow amorphous cobalt hydroxide nanocubes can also be obtained by modifying this route [82]. On the basis of these results, we believe that more interesting and important new types of amorphous nanocages can be obtained by properly tuning the chemical reactions in this fabrication process.

Wang et al. [79] developed a strategy to synthesize amorphous $\mathrm{CoSnO}_{3}$ nanoboxes. They first synthesized porous $\operatorname{CoSn}(\mathrm{OH})_{6}$ nanoboxes in aqueous solution by rapid stoichiometric co-precipitation of $\mathrm{Sn}^{4+}$ and $\mathrm{Co}^{2+}$ in the presence of hydroxyl ions, followed by alkaline etching under ambient conditions. After annealing in $\mathrm{N}_{2}, \mathrm{CoSnO}_{3}$ nanoboxes with a homogenous amorphous texture and high porosity were obtained by thermally induced dehydration of $\mathrm{CoSn}(\mathrm{OH})_{6}$. The robust structure of these $\mathrm{CoSnO}_{3}$ nanoboxes meant they could be coated with amorphous carbon by controlled hydrothermal carbonization of glucose. After hydrothermal treatment, the amorphous texture of the $\mathrm{CoSnO}_{3}$ nanoboxes remained the same because of the relatively low temperature used for carbon coating, as shown in Fig. 11. Following a similar route, Lu's group [84] prepared mesoporous and amorphous $\mathrm{ZnSnO}_{3}$ nanocubes with a size of $\sim 37 \mathrm{~nm}$ coated with a thin porous carbon layer using $\mathrm{ZnSn}(\mathrm{OH})_{6}$ as the active precursor and polydopamine as the carbon precursor. They found that these small single nanocubes would crosslink with each other to form a continuous conductive framework containing interconnected channels with macropores with a width of 74 $\mathrm{nm}$. Recently, zeolitic imidazolate framework-67 (ZIF-67), a classic example of a metal-organic framework, was found to be an interesting precursor to prepare amorphous CoS polyhedral nanocages [83]. The as-obtained rhombic do-
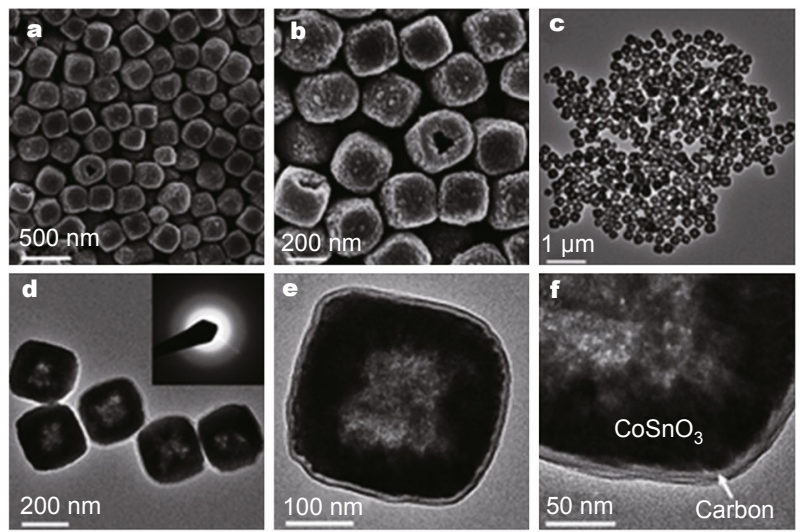

Figure 11 SEM (a and b) and TEM (c and d) images of $\mathrm{CoSnO}_{3} @ \mathrm{C}$ nanoboxes, the SAED pattern of which is shown in the inset of (d); (e) a free-standing $\mathrm{CoSnO}_{3} @ \mathrm{C}$ nanobox; (f) a uniform carbon coating on the surface of a $\mathrm{CoSnO}_{3}$ nanobox. Reprinted with permission from Ref. [79]. Copyright 2013, Royal Society of Chemistry. 
decahedral ZIF-67 was treated as both template and cobalt precursor, and thioacetamide was used as a sulfur source. The reaction process was facile and efficient, simply involving heating the reactants under reflux in ethylene glycol for $1 \mathrm{~h}$. Yang and colleagues [76-78] have also contributed to the synthesis of amorphous hydroxide materials by preparing flower-like spherical nanostructures using a unique electrochemical technique that is simple, green and inexpensive. These spheres and hollow structures are interesting candidates for use in energy storage [94].

\section{APPLICATIONS}

\section{Electrochemical electrode materials}

It is well known that nanomaterials can be a better alternative to the bulk materials for electrodes in electrochemical applications. However, highly crystalline nanoscale electrode materials still face several challenges. Taking Si electrodes as an example, the volume of crystalline $\mathrm{Si}$ anodes expands by $400 \%$ during the lithiation process. As a result, large irreversible capacity losses are typically observed during lithiation/delithiation because anisotropic volume swelling and contraction cause pulverization of the Si and loss of electrical contact with the current collector. Amorphous materials are expected to have smaller and more homogeneous volume expansion than crystalline ones, as well as being effective at releasing volume strain because of their intrinsically isotropic nature [51,84]. Therefore, nanosized amorphous materials should have better cycling performance during the discharge/charge process than bulk crystalline ones. In addition, the high level of disorder in amorphous materials decreases charge transport resistance [10] and enhances the ability to host charge carrier ions [95], the latter of which is illustrated in Fig. 12. The large number of under-coordinated atoms (good electron acceptors) and reactive sites at the surface means that amorphous materials also have the advantage over crystalline ones in their contact with the electrolyte and active substances (electron donors), which favors electrochemical processes. In regard to the merits discussed above, amorphous nanomaterials have already demonstrated their superior performance over bulk crystalline materials in various electrochemical applications, including lithium- and/or sodium-ion batteries $[51,62,66,71,79,84,96-100]$, super- or pseudo-capacitors $[77,78,83]$, electrochemical water splitting [59] and sensors $[72,81]$.

The amorphous $\mathrm{CoSnO}_{3} @ \mathrm{C}$ nanoboxes reported by Wang et al. [79] showed high initial discharge and charge capacities of around 1,410 and $480 \mathrm{~mA} \mathrm{~h} \mathrm{~g}^{-1}$, respectively, as revealed in Fig. 13a. Although a large capacity loss was observed in the first cycle, the $\mathrm{CoSnO}_{3} @ \mathrm{C}$ nanoboxes exhibited a stable capacity retention of nearly $100 \%$ after 200 cycles with a high capacity of over $450 \mathrm{~mA} \mathrm{~h} \mathrm{~g}^{-1}$ from the second cycle onwards. Encouragingly, their lifetime can be extended to as long as 400 cycles with a high capacity of over $450 \mathrm{~mA} \mathrm{~h} \mathrm{~g}^{-1}$ (Fig. 13c). The original structural properties of the $\mathrm{CoSnO}_{3} @ \mathrm{C}$ nanoboxes, including shape, size and structural integrity, were well retained after numerous cycles, indicating the good structural stability of this material. Remarkably, while cycling at high rates of 400-1000 $\mathrm{mA} \mathrm{g}^{-1}$, capacities of 310-450 $\mathrm{mA} \mathrm{h} \mathrm{g}^{-1}$ were still retained, as shown in Fig. 13d. Fig. 13b compares the cycling performance of amorphous $\mathrm{CoSnO}_{3}$ nanoboxes with and without carbon coating, $\mathrm{CoSnO}_{3}$ nanocubes, crystalline Co-Sn-O nanoboxes and commercial $\mathrm{SnO}_{2}$ particles. Both amorphous $\mathrm{CoSnO}_{3}$ and $\mathrm{CoSnO}_{3} @ \mathrm{C}$ nanoboxes exhibit much better cycling performance compared with those of the crystalline materials. The authors believed the atomically mixed, homogeneously amorphous structure of $\mathrm{CoSnO}_{3}$ may contribute to their lithium storage performance because the volume change upon cycling can be partly mitigated in an isotropic, loose/dense structure with high atomic/ionic mobility.

Among the numerous active electrode materials used in electrochemical capacitors, $\mathrm{Ni}(\mathrm{OH})_{2}$ is a promising one. Research on $\mathrm{Ni}(\mathrm{OH})_{2}$ has thus far focused on the crystalline rather than the amorphous phase, despite the impressive electrochemical properties of the latter, which shows improved electrochemical efficiency over its crystalline counterpart because of increased disorder. Li et al. [77] found that electrochemically deposited amorphous $\mathrm{Ni}(\mathrm{OH})_{2}$ nanospheres exhibited high capacitance $\left(2,188 \mathrm{~F} \mathrm{~g}^{-1}\right.$ at a scan rate of $1 \mathrm{mV} \mathrm{s}^{-1}$ ). Asymmetric pseudocapacitors of amorphous $\mathrm{Ni}(\mathrm{OH})_{2}$ also showed high capacitance (153 $\mathrm{F} \mathrm{g}^{-1}$ ), high energy density $\left(35.7 \mathrm{~W} \mathrm{~h} \mathrm{~kg}^{-1}\right.$ at a power density of $490 \mathrm{~W} \mathrm{~kg}^{-1}$ ), and extremely long cycle life (charge retention of $97 \%$ and $81 \%$ after 5,000 and 10,000 cycles, respectively). The integrated electrochemical performance of the amorphous $\mathrm{Ni}(\mathrm{OH})_{2}$ nanospheres is comparable with that of crystalline $\mathrm{Ni}(\mathrm{OH})_{2}$ materials in supercapacitors. The same group also synthesized amorphous $\mathrm{Co}(\mathrm{OH})_{2}$ flower-like nanospheres by a similar method [78]. The as-prepared $\mathrm{Co}(\mathrm{OH})_{2}$ electrode exhibited an ultrahigh capacitance of 1,094 $\mathrm{F} \mathrm{g}^{-1}$ and extremely long cycle life with 95\% charge retention after 8,000 cycles at a nominal scan rate of $100 \mathrm{mV} \mathrm{s}^{-1}$. The authors attributed the high performance of these two hydroxide materials to their internal amorphous structure.

Our group [81] extended the application of amorphous nanomaterials to electrochemical sensing of glucose. We fabricated a sensor to detect glucose by depositing an ink containing amorphous $\mathrm{Ni}(\mathrm{OH})_{2}$ nanoboxes on a glassy carbon electrode (GCE). Fig. 14a shows the cyclic voltammograms $(\mathrm{CVs})$ of $\mathrm{Ni}(\mathrm{OH})_{2} / \mathrm{GCE}$ when reacting with 


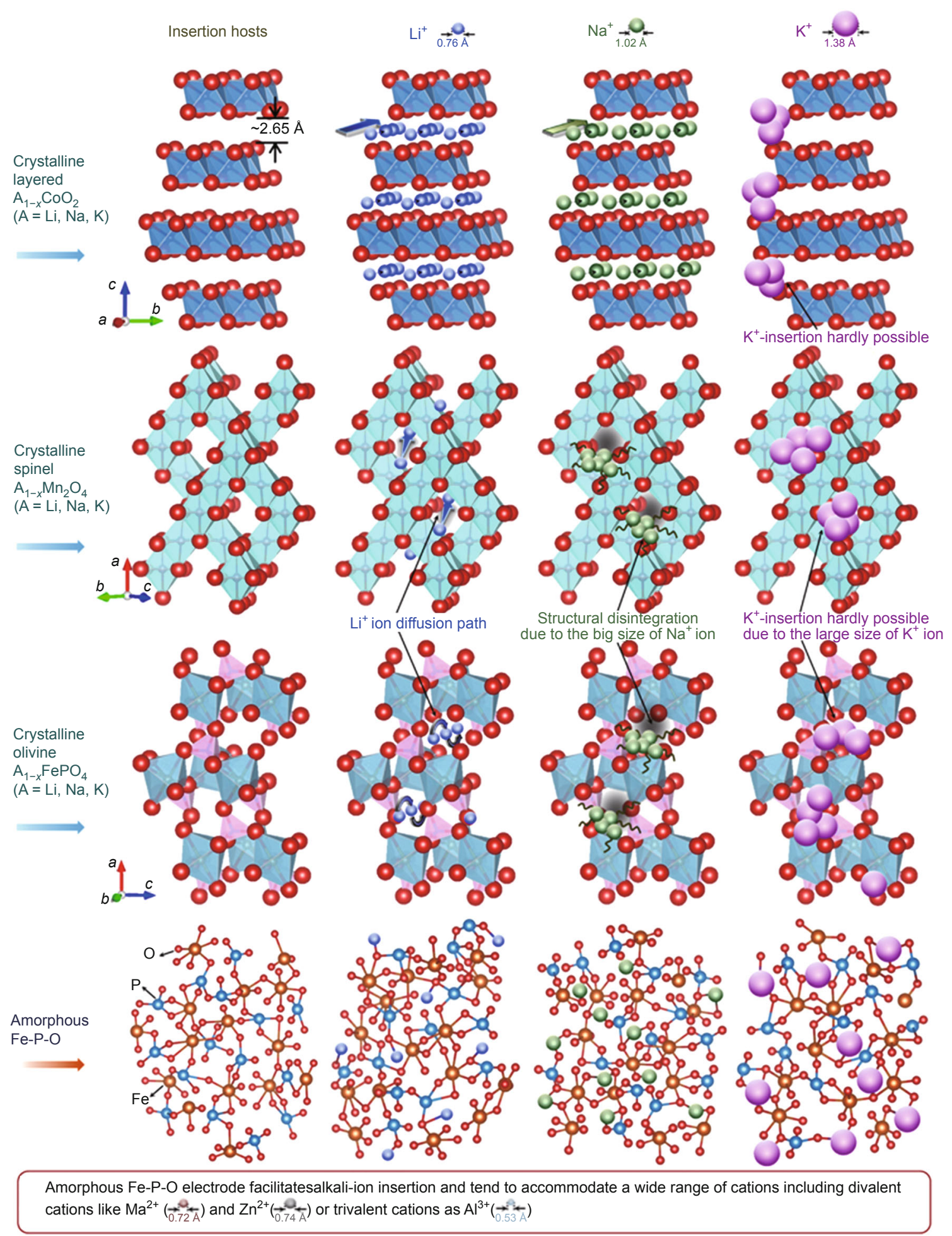

Figure 12 Schematic representation of alkali-ion insertion in crystalline and amorphous electrode hosts. The feasibility of inserting alkali ions (Li/ $\mathrm{Na} / \mathrm{K}$ ) into crystalline (layered, spinel and olivine structured) and amorphous hosts has been evaluated in detail. Although the insertion of Li ions in the presented crystalline and amorphous hosts is feasible, the insertion of Na ions has only been demonstrated in layered-type cathodes. The feasibility of $\mathrm{K}$-ion insertion in crystalline hosts is even more remote because of the relatively large size of $\mathrm{K}$ ions. The importance of amorphous hosts with shortrange ordering is that these hosts facilitate the accommodation/transport of alkali ions irrespective of their size and possibly even charge. Reprinted with permission from Ref. [95]. Copyright 2014, Nature Publishing Group. 

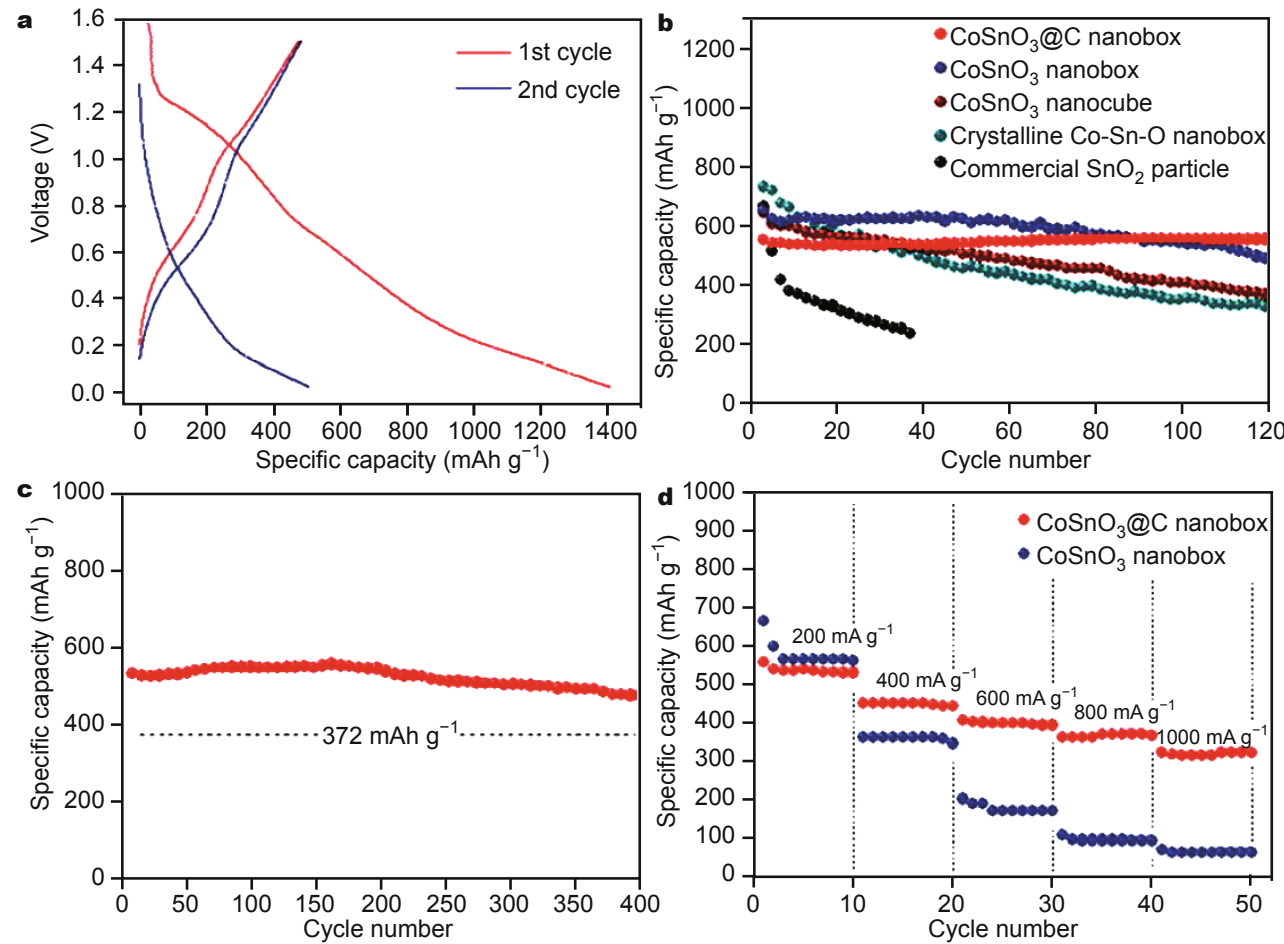

Figure 13 (a) Discharge/charge voltage profiles of $\mathrm{CoSnO}_{3} @ \mathrm{C}$ nanoboxes for the first two cycles; (b) cycling performance of $\mathrm{CoSnO}_{3}$ nanoboxes with and without carbon coating, $\mathrm{CoSnO}_{3}$ nanocubes, crystalline $\mathrm{Co}-\mathrm{Sn}-\mathrm{O}$ nanoboxes and commercial $\mathrm{SnO}_{2}$ particles; (c) long-term cycling stability of $\mathrm{CoSnO}_{3} @ \mathrm{C}$ nanoboxes. All measurements were conducted at a current density of $200 \mathrm{~mA} \mathrm{~g}^{-1}$ between 0.01 and $1.5 \mathrm{~V}$. (d) Rate capability of CoSnO nanoboxes with and without carbon coating measured between 0.01 and $1.5 \mathrm{~V}$ at various current densities. Reprinted with permission from Ref. [79]. Copyright 2013, Royal Society of Chemistry.

various concentrations of glucose in $0.1 \mathrm{M} \mathrm{NaOH}$ solution. The relationship between peak current and glucose concentration is linear over a wide range from $0.5 \mu \mathrm{M}$ to $5 \mathrm{mM}$, which covers the normal physiological concentration of glucose in the human body and should be suitable for quantitative analysis. The sensitivity of the sensor was $487.3 \mu \mathrm{A} \mathrm{mM}^{-1} \mathrm{~cm}^{-2}$ and the limit of detection was as low as $70 \mathrm{nM}(\mathrm{S} / \mathrm{N}=3)$, indicating enhanced sensitivity compared to that of most other nickel-based and some composite materials [81]. Interference effects were investigated by introducing dopamine (DA) and ascorbic acid (AA) to the glucose solutions; the results obtained by differential pulse voltammetry (DPV) are presented in Fig. 14b. It is easy to distinguish glucose from the interferent by considering peak position. In addition, the magnitude of the current from glucose varied little in the presence of interferent, suggesting excellent selectivity of this sensor for glucose. The storage stability of this sensor was examined daily at the same modified electrode over 30 consecutive days. The response to the same concentration of glucose was maintained at $95 \%$ of the initial value after $30 \mathrm{~d}$, so the sensor exhibited good long-term stability.

Kuai et al. [59] evaluated the electrocatalytic water splitting performance of amorphous $\mathrm{Fe}-\mathrm{Ni}-\mathrm{O}_{x}$ nanospheres with different $\mathrm{Fe} / \mathrm{Ni}$ ratios in $1.0 \mathrm{M} \mathrm{KOH}$ at room temperature. $\mathrm{Fe}_{6} \mathrm{Ni}_{10} \mathrm{O}_{x}$ was found to be the best catalyst among the investigated $\mathrm{Fe}-\mathrm{Ni}-\mathrm{O}_{x}$ series, with an overpotential of as low as $0.286 \mathrm{~V}\left(10 \mathrm{~mA} \mathrm{~cm}{ }^{-2}\right)$ and Tafel slope of $48 \mathrm{mV}$ decade $^{-1}$ for the electrochemical oxygen evolution reaction. They also compared the catalytic activity of amorphous Fe$\mathrm{Ni}$ oxide materials and their crystalline counterparts obtained after annealing. About $150 \mathrm{mV}$ more overpotential for both $\mathrm{Fe}_{6} \mathrm{Ni}_{10}\left(400^{\circ} \mathrm{C}\right)$ and $\mathrm{Fe}_{6} \mathrm{Ni}_{10}\left(500^{\circ} \mathrm{C}\right)$ was needed to achieve a current density of $10 \mathrm{~mA} \mathrm{~cm}{ }^{-2}$ compared with that of the original amorphous $\mathrm{Fe}_{6} \mathrm{Ni}_{10}$ sample.

\section{Optical response}

The photocatalytic activity of an amorphous hcp $\mathrm{TiO}_{2}$ nanocolumn array was estimated by Li et al. [70] based on the decomposition of stearic acid under ultraviolet (UV) illumination by monitoring Fourier transform infrared spectra. The bands at 2,919 and $2,849 \mathrm{~cm}^{-1}$ are related to the asymmetric $\left(v_{\text {asymmCH}}\right)$ and symmetric $\left(v_{\text {symmCH}_{2}}\right)$ stretching modes of the methylene group of stearic acid, respectively. These values for the methylene group stretching modes are generally regarded as evidence of the formation of a dense, well-ordered, self-assembled monolayer of stearic acid on the oxide surface. With increasing UV irradiation time, the 

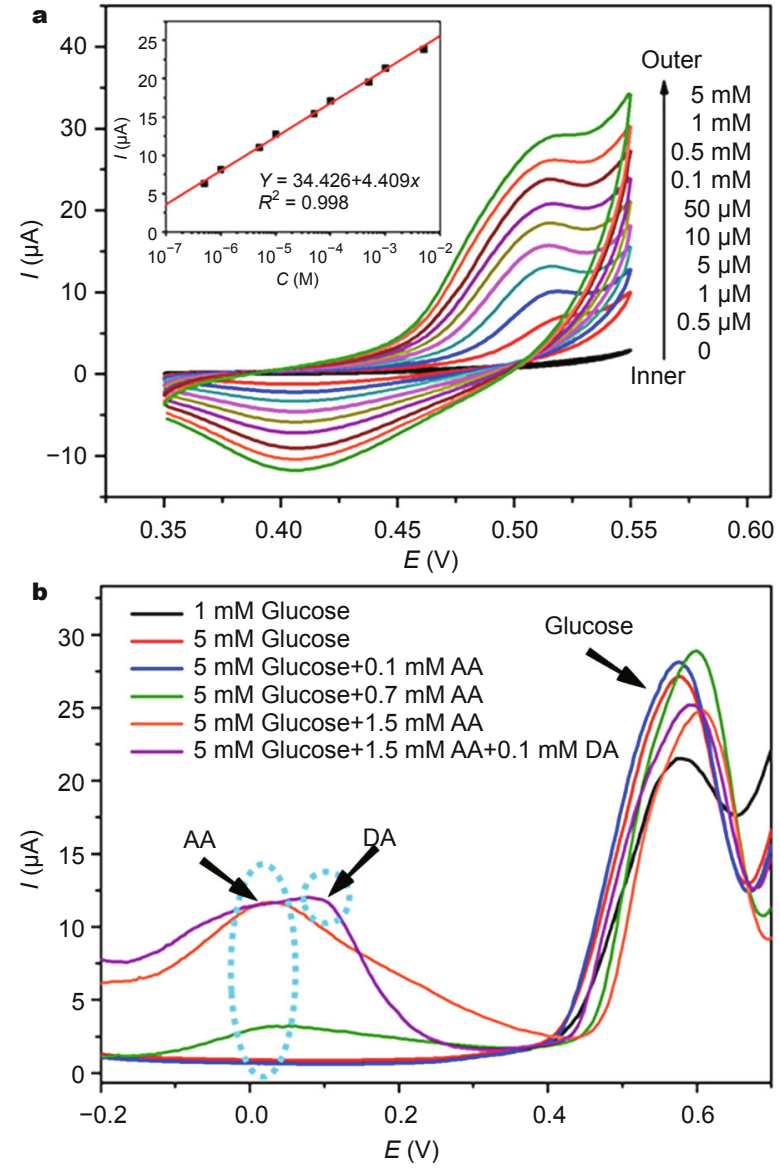

Figure 14 (a) $\mathrm{CV}$ s obtained at $\mathrm{Ni}(\mathrm{OH})_{2}$ nanoboxes/GCE in $0.1 \mathrm{M} \mathrm{NaOH}$ solution with various concentrations of glucose at a scan rate of $0.1 \mathrm{~V} \mathrm{~s}^{-1}$; inset is the oxidation peak currents of the $\mathrm{CVs}$ as a function of glucose concentration. (b) DPV of the $\mathrm{Ni}(\mathrm{OH})_{2}$ nanoboxes/GCE in $0.1 \mathrm{M} \mathrm{NaOH}$ with different concentrations of glucose, AA and DA. Reprinted with permission from Ref. [81]. Copyright 2013, Wiley-VCH Publishers, Inc.

intensity of the vibrational bands of the methylene group gradually decreases and almost completely disappeares after $25 \mathrm{~min}$, as shown in Fig. 15a. The decrease in intensity of the $\mathrm{C}-\mathrm{H}$ vibrational bands suggests that the stearic acid is gradually photodegraded by the $\mathrm{TiO}_{2}$ films under UV irradiation. Fig. 15b presents the degradation curves of a stearic acid film on a $\mathrm{Si}$ wafer, an amorphous $\mathrm{TiO}_{2}$ film formed by PLD without using a colloidal monolayer, an hcp amorphous $\mathrm{TiO}_{2}$ nanocolumn array on a colloidal monolayer and an anatase $\mathrm{TiO}_{2}$ nanocolumn array. $\mathrm{TiO}_{2}$ exhibited degraded stearic acid efficiently and the hcp amorphous $\mathrm{TiO}_{2}$ nanocolumn array on a colloidal monolayer demonstrated better performance than the amorphous film and anatase nanocolumn array.

Choi et al. [63] incorporated amorphous $\mathrm{Zn}_{2} \mathrm{SnO}_{4}$ nanofibers in dye-sensitized solar cells (DSSCs). Three different sensitizers, two organic dyes with donor-conjugate-acceptor structure and a ruthenium complex (N719) dye were
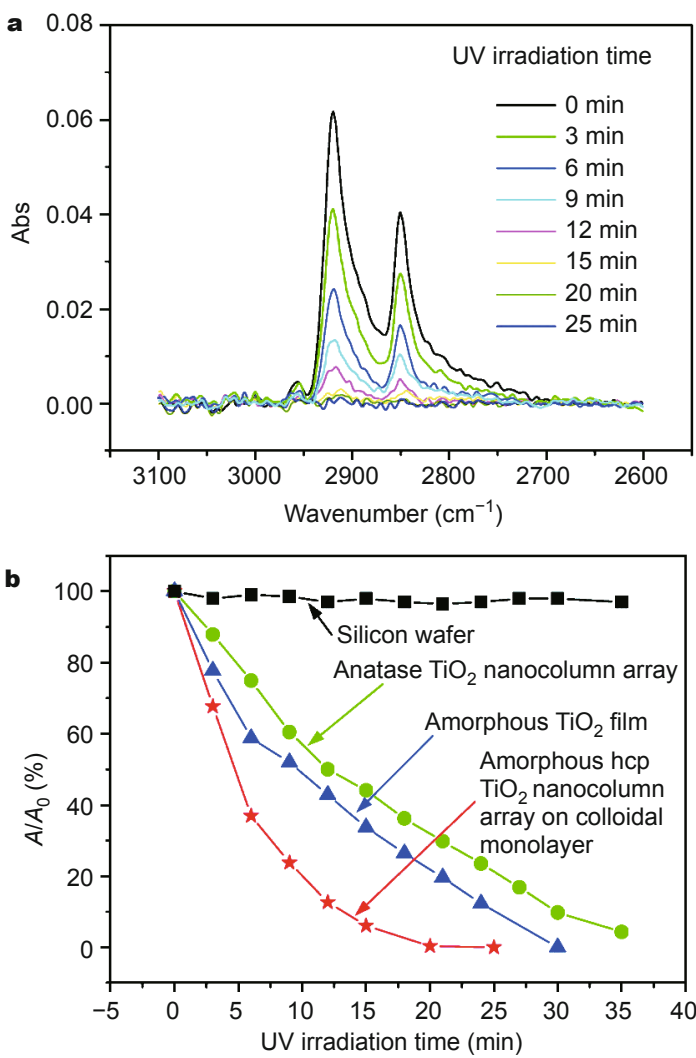

Figure 15 (a) Photocatalytic activity of an hcp amorphous $\mathrm{TiO}_{2}$ nanocolumn array with a PS colloidal monolayer; (b) evaluation of the photocatalytic activity of different substrates based on the absorbance ratio $A$ / $A_{0}$ as a function of UV irradiation time, $A$ and $A_{0}$ are the absorbance after UV irradiation and that of the initial surface, respectively. Reprinted with permission from Ref. [70]. Copyright 2008, American Chemical Society.

used to fabricate $\mathrm{Zn}_{2} \mathrm{SnO}_{4}$ nanofiber-based DSSCs and then their performance was investigated. Remarkably, the organic dye-sensitized DSSCs displayed markedly improved performance ( 2.5 times higher) than that of the N719-sensitized DSSCs. These devices based on a $3 \mu \mathrm{m}-$ thick $\mathrm{Zn}_{2} \mathrm{SnO}_{4}$ electrode using the new sensitizer in conjunction with a liquid electrolyte show promising photovoltaic conversion of up to $3.7 \%$ under standard AM $1.5 \mathrm{G}$ sunlight $\left(100 \mathrm{~mW} \mathrm{~cm}^{-2}\right)$. This work highlights the potential of amorphous $\mathrm{Zn}_{2} \mathrm{SnO}_{4}$ electrodes for the development of efficient organic-sensitized DSSCs and offers a future perspective for the development of solid-state DSSCs.

Cui's group [73] compared the optical absorption properties of a-Si:H thin films, NW arrays and NC arrays. At $488 \mathrm{~nm}$, the absorption of the NC sample is $98.4 \%$ around normal incidence, which is considerably higher than that of the NW arrays (85\%) and thin films (75\%). At incident angles of up to $60^{\circ}$, the total absorption is maintained above $90 \%$ for the NCs, which compares favorably with $70 \%$ for the NWs and $45 \%$ for the thin films. These absorption measurements were also carried out over a broad range of 
wavelengths $(400-800 \mathrm{~nm})$ that covered most of the useful spectrum for a-Si:H solar cells. Between 400 and $650 \mathrm{~nm}$, the measured absorption of the NC arrays was maintained above $93 \%$, which was much higher than that of the NW arrays of $75 \%$ and thin films of $64 \%$. The total absorption of the NCs decreased to $88 \%$ at $700 \mathrm{~nm}$, which corresponded to the a-Si : $\mathrm{H}$ band gap $(1.75 \mathrm{eV})$, but was still better than that of the NWs (70\%) and thin films (53\%). These results indicate that the novel a-Si:H NCs may be suitable for lowcost, large-area solar cells.

\section{SUMMARY AND OUTLOOK}

Applications and fundamental scientific studies that require high-quality multifunctional nanostructures continue to expand. These areas demand rigorous control of the structure of nanoscale materials, including their size, shape, composition and assembly, in a manner that facilitates synergistic interactions, and thus establishes guidelines for further exploration. Compared with the structure control of nanocrystals achieved to date, that of amorphous nanomaterials, shape manipulation in particular, is far behind. Nevertheless, some innovative approaches to tailor the morphology of amorphous nanomaterials have been realized, and were presented in this review. Basically, these approaches can be divided into the following four categories: (1) employing surfactants to adsorb on the surface of NPs to affect their growth (for nanospheres); (2) using specific techniques, such as electrospinning or laser vapor deposition, to guide the materials to grow in one direction (for NWs and nanofibers); (3) using substrates for oxidation, etching, or deposition (for arrays); (4) introducing hard templates into solution-based systems (for nanopolyhedra). The compositions of these amorphous nanomaterials are mainly $3 \mathrm{~d}$ transition-metal compounds and elementary substances of the main group IV. The primary morphologies of amorphous nanomaterials reported so far are $0 \mathrm{D}, 1 \mathrm{D}$ and $3 \mathrm{D}$; few 2D structures have been fabricated. The properties of amorphous nanomaterials have also been investigated, especially their electrochemical and optical parameters. These well-defined and regular-shaped amorphous nanomaterials demonstrate comparable and sometimes even better performance than other conventional amorphous materials (films and particles) and crystalline nanomaterials, showing their potential value for applications.

We should be aware that most of the strategies used to prepare amorphous nanomaterials presented in this review can only be regarded as loose tailoring, and are still far from finely controlling the shape of nanostructures. Each route is normally suitable for just one kind of shape or composition, which does not satisfy the requirements of nanoscience and nanotechnology. Developing a general method to fabricate diverse morphologies or compositions is still a challenge. Only now are we beginning to investigate the largely uncharted atomic structure of amorphous materials. As an emerging discipline, many concepts about the structures, dynamics, and thermodynamics of amorphous nanomaterials have yet to be established. Further effort needs to be devoted to surpassing the conventional ideological framework of crystalline solids. Theoretical simulations or calculations will be indispensable for providing clues to describe the complicated internal structure of amorphous materials, as well as to understand the relationship between their properties and structure. Therefore, it is of urgency to develop proper computational methods for amorphous materials. With regard to applications, how to effectively improve the stability and electronic conductivity of amorphous nanomaterials are two essential problems that we need to solve.

Fortunately, opportunities always stand beside challenges. There is still plenty of room to explore the amorphous world. In this paper, we reviewed some recent achievements in tailoring the nanostructures of amorphous materials and their applications. This is just the tip of the iceberg in the study of amorphous nanomaterials. As researchers continue to develop scientific tools to understand concepts related to amorphous structure, additional applications will emerge. The controllable synthesis of amorphous nanostructures will undoubtedly advance the discipline of nanomaterials, and make these materials become much more sophisticated, diverse, and mainstream.

Received 16 November 2014; accepted 11 December 2014; published online 20 January 2015

1 Wang W. The nature and properties of amorphous matter. Prog Phys, 2013, 33: 177-351

2 Hirata A, Kang LJ, Fujita T, et al. Geometric frustration of icosahedron in metallic glasses. Science, 2013, 341: 376-379

3 Hirata A, Guan P, Fujita T, et al. Direct observation of local atomic order in a metallic glass. Nat Mater, 2011, 10: 28-33

4 Sheng HW, Luo WK, Alamgir FM, Bai JM, Ma E. Atomic packing and short-to-medium-range order in metallic glasses. Nature, 2006, 439: 419-425

5 Miracle DB. A structural model for metallic glasses. Nat Mater, 2004, 3: 697-702

6 Sheng HW, Liu HZ, Cheng YQ, et al. Polyamorphism in a metallic glass. Nat Mater, 2007, 6: 192-197

7 Zeng Q, Sheng H, Ding Y, et al. Long-range topological order in metallic glass. Science, 2011, 332: 1404-1406

8 Deringer VL, Zhang W, Lumeij M, et al. Bonding nature of local structural motifs in amorphous GeTe. Angew Chem Int Ed, 2014, 53: $10817-10820$

9 Buchholz DB, Ma Q, Alducin D, et al. The structure and properties of amorphous indium oxide. Chem Mater, 2014, 26: 5401-5411

10 Tian F, Radin MD, Siegel DJ. Enhanced charge transport in amorphous $\mathrm{Li}_{2} \mathrm{O}_{2}$. Chem Mater, 2014, 26: 2952-2959

11 Wang J, Li R, Hua N, Zhang T. Co-based ternary bulk metallic glasses with ultrahigh strength and plasticity. J Mater Res, 2011, 26: 
2072-2079

12 Liu YH, Wang G, Wang RJ, et al. Super plastic bulk metallic glasses at room temperature. Science, 2007, 315: 1385-1388

13 Smith RDL, Prévot MS, Fagan RD, et al. Photochemical route for accessing amorphous metal oxide materials for water oxidation catalysis. Science, 2013, 340: 60-63

14 Wang JQ, Liu YH, Chen MW, et al. Rapid degradation of azo dye by Fe-based metallic glass powder. Adv Funct Mater, 2012, 22 2567-2570

15 Luo Q, Zhao DQ, Pan MX, Wang WH. Magnetocaloric effect in Gd-based bulk metallic glasses. Appl Phys Lett, 2006, 89: 081914

16 Luo Q, Zhao DQ, Pan MX, Wang WH. Magnetocaloric effect of Ho-, Dy-, and Er-based bulk metallic glasses in helium and hydrogen liquefaction temperature range. Appl Phys Lett, 2007, 90: 211903

17 Huo JT, Zhao DQ, Bai HY, Axinte E, Wang WH. Giant magnetocaloric effect in Tm-based bulk metallic glasses. J Non-Cryst Solids, 2013, 359: 1-4

18 Buchholz DB, Liu J, Marks TJ, Zhang M, Chang RPH. Control and characterization of the structural, electrical, and optical properties of amorphous zinc-indium-tin oxide thin films. ACS Appl Mater Interfaces, 2009, 1: 2147-2153

19 Cowell Iii EW, Knutson CC, Wager JF, Keszler DA. Amorphous metal/oxide nanolaminate. ACS Appl Mater Interfaces, 2010, 2 1811-1813

20 Liu J, Buchholz DB, Hennek JW, et al. All-amorphous-oxide transparent, flexible thin-film transistors. Efficacy of bilayer gate dielectrics. J Am Chem Soc, 2010, 132: 11934-11942

21 Yang Y, Fei H, Ruan G, Xiang C, Tour JM. Efficient electrocatalytic oxygen evolution on amorphous nickel-cobalt binary oxide nanoporous layers. ACS Nano, 2014, 8: 9518-9523

22 Tian L, Cheng YQ, Shan ZW, et al. Approaching the ideal elastic limit of metallic glasses. Nat Commun, 2012, 3: 609

23 Liaw BJ, Chiang SJ, Chen SW, Chen YZ. Preparation and catalysis of amorphous $\mathrm{CoNiB}$ and polymer-stabilized $\mathrm{CoNiB}$ catalysts for hydrogenation of unsaturated aldehydes. Appl Catal A-General, 2008, 346: $179-188$

24 Lee I, Kim D, Kal J, et al. Quasi-amorphous colloidal structures for electrically tunable full-color photonic pixels with angle-independency. Adv Mater, 2010, 22: 4973-4977

25 Wang XL, Han WQ, Chen H, et al. Amorphous hierarchical porous $\mathrm{GeO}_{x}$ as high-capacity anodes for $\mathrm{Li}$ ion batteries with very long cycling life. J Am Chem Soc, 2011, 133: 20692-20695

26 Hall JW, Membreno N, Wu J, et al. Low-temperature synthesis of amorphous $\mathrm{FeP}_{2}$ and its use as anodes for $\mathrm{Li}$ ion batteries. J Am Chem Soc, 2012, 134: 5532-5535

27 Nguyen DT, Nguyen CC, Kim JS, Kim JY, Song SW. Facile synthesis and high anode performance of carbon fiber-interwoven amorphous nano-SiO $x$ /graphene for rechargeable lithium batteries. ACS Appl Mater Interfaces, 2013, 5: 11234-11239

28 Suryanto BHR, Lu X, Zhao C. Layer-by-layer assembly of transparent amorphous $\mathrm{Co}_{3} \mathrm{O}_{4}$ nanoparticles/graphene composite electrodes for sustained oxygen evolution reaction. J Mater Chem A, 2013, 1: 12726-12731

29 Morales-Guio CG, Hu X. Amorphous molybdenum sulfides as hydrogen evolution catalysts. Acc Chem Res, 2014, 47: 2671-2681

30 Ko M, Chae S, Jeong S, Oh P, Cho J. Elastic a-silicon nanoparticle backboned graphene hybrid as a self-compacting anode for highrate lithium ion batteries. ACS Nano, 2014, 8: 8591-8599

31 Burda C, Chen X, Narayanan R, El-Sayed MA. Chemistry and properties of nanocrystals of different shapes. Chem Rev, 2005, 105: 1025-1102

32 Zhou K, Li Y. Catalysis based on nanocrystals with well-defined facets. Angew Chem Int Ed, 2012, 51: 602-613

33 Huang X, Tang S, Mu X, et al. Freestanding palladium nanosheets with plasmonic and catalytic properties. Nat Nanotechnol, 2011, 6: 28-32

34 Nai J, Chen Z, Li H, et al. Structure-dependent electrocatalysis of $\mathrm{Ni}(\mathrm{OH})_{2}$ hourglass-like nanostructures towards L-histidine. Chem Eur J, 2013, 19: 501-508

35 Zhang DF, Zhang H, Guo L, et al. Delicate control of crystallographic facet-oriented $\mathrm{Cu}_{2} \mathrm{O}$ nanocrystals and the correlated adsorption ability. J Mater Chem, 2009, 19: 5220-5225

36 Shang Y, Zhang D, Guo L. CuCl-intermediated construction of short-range-ordered $\mathrm{Cu}_{2} \mathrm{O}$ mesoporous spheres with excellent adsorption performance. J Mater Chem, 2012, 22: 856-861

37 Shang Y, Sun D, Shao Y, et al. A facile top-down etching to create a $\mathrm{Cu}_{2} \mathrm{O}$ jagged polyhedron covered with numerous $\{110\}$ edges and $\{111\}$ corners with enhanced photocatalytic activity. Chem Eur J, 2012, 18: 14261-14266

38 Wang H, Gao J, Guo T, et al. Facile synthesis of AgBr nanoplates with exposed $\{111\}$ facets and enhanced photocatalytic properties. Chem Commun, 2012, 48: 275-277

39 Xu D, Bliznakov S, Liu Z, Fang J, Dimitrov N. Composition-dependent electrocatalytic activity of Pt-Cu nanocube catalysts for formic acid oxidation. Angew Chem Int Ed, 2010, 49: 1282-1285

40 Abe H, Matsumoto F, Alden LR, et al. Electrocatalytic performance of fuel oxidation by $\mathrm{Pt}_{3}$ Ti nanoparticles. J Am Chem Soc, 2008, 130: 5452-5458

41 Talapin DV, Shevchenko EV, Bodnarchuk MI, et al. Quasicrystalline order in self-assembled binary nanoparticle superlattices. Nature, 2009, 461: 964-967

42 Shang Y, Shao YM, Zhang DF, Guo L. Recrystallization-induced self-assembly for the growth of $\mathrm{Cu}_{2} \mathrm{O}$ superstructures. Angew Chem Int Ed, 2014, 53: 11514-11518

43 Xu AW, Yu Q, Dong WF, Antonietti M, Cölfen H. Stable amorphous $\mathrm{CaCO}_{3}$ microparticles with hollow spherical superstructures stabilized by phytic acid. Adv Mater, 2005, 17: 2217-2221

44 Ajikumar PK, Wong LG, Subramanyam G, Lakshminarayanan R, Valiyaveettil S. Synthesis and characterization of monodispersed spheres of amorphous calcium carbonate and calcite spherules. Cryst Growth Des, 2005, 5: 1129-1134

45 Faatz M, Cheng W, Wegner G, et al. Mechanical strength of amorphous $\mathrm{CaCO}_{3}$ colloidal spheres. Langmuir, 2005, 21: 6666-6668

46 Shen Q, Wei H, Zhou Y, et al. Properties of amorphous calcium carbonate and the template action of vaterite spheres. J Phys Chem B, 2006, 110: 2994-3000

47 Huang SC, Naka K, Chujo Y. A carbonate controlled-addition method for amorphous calcium carbonate spheres stabilized by poly(acrylic acid)s. Langmuir, 2007, 23: 12086-12095

48 Pell LE, Schricker AD, Mikulec FV, Korgel BA. Synthesis of amorphous silicon colloids by trisilane thermolysis in high temperature supercritical solvents. Langmuir, 2004, 20: 6546-6548

49 Eiblmeier J, Kellermeier M, Deng M, et al. Bottom-up self-assembly of amorphous core-shell-shell nanoparticles and biomimetic crystal forms in inorganic silica-carbonate systems. Chem Mater, 2013, 25: $1842-1851$

50 Luckarift HR, Dickerson MB, Sandhage KH, Spain JC. Rapid, room-temperature synthesis of antibacterial bionanocomposites of lysozyme with amorphous silica or titania. Small, 2006, 2: 640-643

51 Murugesan S, Harris JT, Korgel BA, Stevenson KJ. Copper-coated amorphous silicon particles as an anode material for lithium-ion batteries. Chem Mater, 2012, 24: 1306-1315

52 Harris JT, Hueso JL, Korgel BA. Hydrogenated amorphous silicon (a-Si:H) colloids. Chem Mater, 2010, 22: 6378-6383

53 Kaur G, Iqbal M, Bakshi MS. Biomineralization of fine selenium crystalline rods and amorphous spheres. J Phys Chem C, 2009, 113: 13670-13676

54 Sugimoto T, Kojima T. Formation mechanism of amorphous $\mathrm{TiO}_{2}$ spheres in organic solvents. 1. Roles of ammonia. J Phys Chem C, 
2008, 112: 18760-18771

55 Sugimoto T, Kojima T. Formation mechanism of amorphous $\mathrm{TiO}_{2}$ spheres in organic solvents. 2. Kinetics of precipitation. J Phys Chem C, 2008, 112: 18437-18444

56 Kojima T, Sugimoto T. Formation mechanism of amorphous $\mathrm{TiO}_{2}$ spheres in organic solvents. 3. Effects of water, temperature, and solvent composition. J Phys Chem C, 2008, 112: 18445-18454

57 Wu MM, Wang GG, Xu HF, et al. Hollow spheres based on mesostructured lead titanate with amorphous framework. Langmuir, 2003, 19: 1362-1367

58 Zhu Z, Ma J, Xu L, et al. Facile synthesis of Co-B amorphous alloy in uniform spherical nanoparticles with enhanced catalytic properties. ACS Catal, 2012, 2: 2119-2125

59 Kuai L, Geng J, Chen C, et al. A reliable aerosol-spray-assisted approach to produce and optimize amorphous metal oxide catalysts for electrochemical water splitting. Angew Chem Int Ed, 2014, 53: 7547-7551

60 Fang Y, Xiao L, Qian J, et al. Mesoporous amorphous $\mathrm{FePO}_{4}$ nanospheres as high-performance cathode material for sodium-ion batteries. Nano Lett, 2014, 14: 3539-3543

61 Cho S, Jang JW, Jung A, et al. Formation of amorphous zinc citrate spheres and their conversion to crystalline $\mathrm{ZnO}$ nanostructures. Langmuir, 2011, 27: 371-378

62 Shen JM, Xu L, Liu YG, et al. Wet chemistry self-seeded surfacedeposition process toward amorphous carbon nanotubes and their electrochemical application. Chem Mater, 2008, 20: 3034-3041

63 Choi SH, Hwang D, Kim DY, et al. Amorphous zinc stannate $\left(\mathrm{Zn}_{2} \mathrm{Sn}\right.$ $\mathrm{O}_{4}$ ) nanofibers networks as photoelectrodes for organic dye-sensitized solar cells. Adv Fun Mater, 2013, 23: 3146-3155

64 Zheng J, Song X, Li X, Pu Y. Large-scale production of amorphous silicon oxynitride nanowires by nickel-catalyzed transformation of silicon wafers in $\mathrm{NH}_{3}$ plasma. J Phys Chem C, 2008, 112: 27-34

65 Kobayashi K, Kokai F, Sakurai N, Yasuda H. Silicon-catalyzed growth of amorphous $\mathrm{SiO}_{x}$ nanowires by laser vaporization of $\mathrm{Si}$ and $\mathrm{Si} / \mathrm{SiO}_{2}$. J Phys Chem C, 2013, 117: 25169-25174

66 Cui LF, Ruffo R, Chan CK, Peng H, Cui Y. Crystalline-amorphous core-shell silicon nanowires for high capacity and high current battery electrodes. Nano Lett, 2009, 9: 491-495

67 Adachi MM, Anantram MP, Karim KS. Optical properties of crystalline-amorphous core-shell silicon nanowires. Nano Lett, 2010 , 10: 4093-4098

68 Kőrösi L, Papp S, Csapó E, et al. A short solid-state synthesis leading to titanate compounds with porous structure and nanosheet morphology. Micropor Mesopor Mat, 2012, 147: 53-58

69 Xu C, Zeng Y, Rui X, et al. Amorphous iron oxyhydroxide nanosheets: synthesis, Li storage, and conversion reaction kinetics. J Phys Chem C, 2013, 117: 17462-17469

70 Li Y, Sasaki T, Shimizu Y, Koshizaki N. Hexagonal-close-packed, hierarchical amorphous $\mathrm{TiO}_{2}$ nanocolumn arrays: transferability, enhanced photocatalytic activity, and superamphiphilicity without UV irradiation. J Am Chem Soc, 2008, 130: 14755-14762

71 Bi Z, Paranthaman MP, Menchhofer PA, et al. Self-organized amorphous $\mathrm{TiO}_{2}$ nanotube arrays on porous $\mathrm{Ti}$ foam for rechargeable lithium and sodium ion batteries. J Power Sources, 2013, 222: 461466

$72 \mathrm{Lu}$ HF, Li F, Liu G, et al. Amorphous $\mathrm{TiO}_{2}$ nanotube arrays for lowtemperature oxygen sensors. Nanotechnology, 2008, 19: 405504

73 Zhu J, Yu Z, Burkhard GF, et al. Optical absorption enhancement in amorphous silicon nanowire and nanocone arrays. Nano Lett, 2009, 9: 279-282

74 Lee K, Wagermaier W, Masic A, et al. Self-assembly of amorphous calcium carbonate microlens arrays. Nat Commun, 2012, 3: 725

75 Chueh YL, Fan Z, Takei K, et al. Black Ge based on crystalline/ amorphous core/shell nanoneedle arrays. Nano Lett, 2010, 10: 520523
76 Li HB, Liu P, Liang Y, Xiao J, Yang GW. Amorphous nickel hydroxide nanospheres by a green electrochemistry technique: structure, morphology and magnetism. Cryst Eng Comm, 2013, 15: 4054-4057

77 Li HB, Yu MH, Wang FX, et al. Amorphous nickel hydroxide nanospheres with ultrahigh capacitance and energy density as electrochemical pseudocapacitor materials. Nat Commun, 2013, 4: 1894

$78 \mathrm{Li} \mathrm{HB}, \mathrm{Yu} \mathrm{MH}, \mathrm{Lu} \mathrm{XH}$, et al. Amorphous cobalt hydroxide with superior pseudocapacitive performance. ACS Appl Mater Interfaces, 2014, 6: 745-749

79 Wang Z, Wang Z, Liu W, Xiao W, Lou XW. Amorphous $\mathrm{CoSnO}_{3} @ \mathrm{C}$ nanoboxes with superior lithium storage capability. Energy Envir Sci, 2013, 6: 87-91

80 Nai J, Tian Y, Guan X, Guo L. Pearson's principle inspired generalized strategy for the fabrication of metal hydroxide and oxide nanocages. J Am Chem Soc, 2013, 135: 16082-16091

81 Nai J, Wang S, Bai Y, Guo L. Amorphous $\mathrm{Ni}(\mathrm{OH})_{2}$ nanoboxes: fast fabrication and enhanced sensing for glucose. Small, 2013, 9: 3147-3152

82 Guan X, Nai J, Zhang Y, et al. CoO hollow Cube/reduced graphene oxide composites with enhanced lithium storage capability. Chem Mater, 2014, 26: 5958-5964

83 Jiang Z, Lu W, Li Z, et al. Synthesis of amorphous cobalt sulfide polyhedral nanocages for high performance supercapacitors. J Mater Chem A, 2014, 2: 8603-8606

84 Han F, Li WC, Lei C, et al. Selective formation of carbon-coated, metastable amorphous $\mathrm{ZnSnO}_{3}$ nanocubes containing mesopores for use as high-capacity lithium-ion battery. Small, 2014, 10: 2637-2644

85 Xie JL, Guo CX, Li CM. Construction of one-dimensional nanostructures on graphene for efficient energy conversion and storage. Energy Envir Sci, 2014, 7: 2559-2579

86 Devan RS, Patil RA, Lin JH, Ma YR. One-dimensional metal-oxide nanostructures: recent developments in synthesis, characterization, and applications. Adv Funct Mater, 2012, 22: 3326-3370

87 Liusman C, Li H, Lu G, et al. Surface-enhanced Raman scattering of Ag-Au nanodisk heterodimers. J Phys Chem C, 2012, 116: 10390-10395

88 Liusman C, Li S, Chen X, et al. Free-standing bimetallic nanorings and nanoring arrays made by on-wire lithography. ACS Nano, 2010, 4: 7676-7682

89 Ma CB, Qi X, Chen B, et al. $\mathrm{MoS}_{2}$ nanoflower-decorated reduced graphene oxide paper for high-performance hydrogen evolution reaction. Nanoscale, 2014, 6: 5624-5629

$90 \mathrm{Wu}$ J, Li H, Yin Z, et al. Layer thinning and etching of mechanically exfoliated $\mathrm{MoS}_{2}$ nanosheets by thermal annealing in air. Small, 2013, 9: 3314-3319

91 Yin Z, Wang Z, Du Y, et al. Full solution-processed synthesis of all metal oxide-based tree-like heterostructures on fluorine-doped tin oxide for water splitting. Adv Mater, 2012, 24: 5374-5378

92 Zhang H, Jin M, Xia Y. Noble-metal nanocrystals with concave surfaces: synthesis and applications. Angew Chem Int Ed, 2012, 51: 7656-7673

93 Huang $\mathrm{MH}$, Lin PH. Shape-controlled synthesis of polyhedral nanocrystals and their facet-dependent properties. Adv Funct Mater, 2012, 22: 14-24

94 Zhu J, Yin Z, Yang D, et al. Hierarchical hollow spheres composed of ultrathin $\mathrm{Fe}_{2} \mathrm{O}_{3}$ nanosheets for lithium storage and photocatalytic water oxidation. Energy Envir Sci, 2013, 6: 987-993

95 Mathew V, Kim S, Kang J, et al. Amorphous iron phosphate: potential host for various charge carrier ions. NPG Asia Mater, 2014, 6: e138

96 Xiong H, Yildirim H, Shevchenko EV, et al. Self-improving anode for lithium-ion batteries based on amorphous to cubic phase transition in $\mathrm{TiO}_{2}$ nanotubes. J Phys Chem C, 2011, 116: 3181-3187

97 Xiong H, Slater MD, Balasubramanian M, Johnson CS, Rajh T. Amorphous $\mathrm{TiO}_{2}$ nanotube anode for rechargeable sodium ion bat- 
teries. J Phys Chem Lett, 2011, 2: 2560-2565

98 Uchaker E, Zheng YZ, Li S, et al. Better than crystalline: amorphous vanadium oxide for sodium-ion batteries. J Mater Chem A, 2014 2: $18208-18214$

99 Chae OB, Kim J, Park I, et al. Reversible lithium storage at highly populated vacant sites in an amorphous vanadium pentoxide electrode. Chem Mater, 2014, 26: 5874-5881

100 Kim Y, Park Y, Choi A, et al. An amorphous red phosphorus/carbon composite as a promising anode material for sodium ion batteries. Adv Mater, 2013, 25: 3045-3049
Acknowledgements This work was supported by the National Natural Science Foundation of China (51272012 and 21471013).

Author contributions Nai J and Kang $\mathrm{J}$ collected and categorized the literatures; Nai J wrote the manuscript. Guo L supervised the manuscript writing and provided advice. All authors contributed to the general discussion.

Conflict of interest The authors declare that they have no conflict of interest.

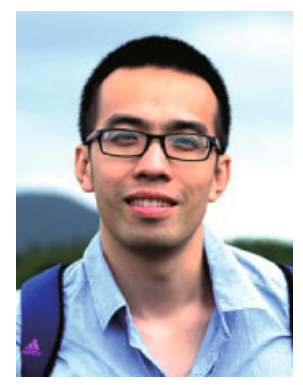

Jianwei Nai was born in Guangxi, China in 1985. He received his PhD degree in micro-and nanotechnology from Beihang University, Beijing, China in 2014. He then joined Prof. Lin Guo's group as a postdoctoral scholar between 2/2014-10/2014. He is now employed as a postdoctoral researcher in Prof. Dmitri Talapin's laboratory at the University of Chicago, USA. His current research interests focus on the controlled synthesis of nanomaterials and their application in electrocatalysis.
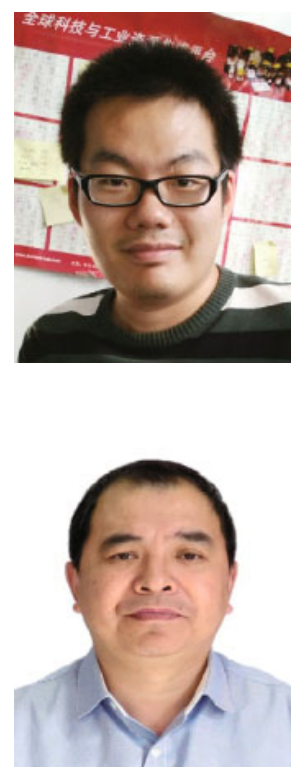

Jianxin Kang was born in Shandong, China in 1989. He received his BSc degree from the School of Chemistry and Environment, Beihang University in 2010. He joined Prof. Lin Guo's group as a PhD candidate in 2010. His research interests are the controlled synthesis and applications of nanomaterials.
Lin Guo was born in 1964. He received his PhD degree from Beijing University of Institute of Technology, Beijing, China, in 1997. He is currently a professor at the School of Chemistry and Environment, Beihang University. His research focuses on the development of new methods for the synthesis of nanostructured materials with potential for future applications and the characterization of their unique properties.

中文摘要 非晶纳米材料是非晶态物质中十分重要的成员, 并已成为先进材料研究领域的一个崭新分支. 然而, 实现对非晶纳米材料的 形貌控制却是十分困难的, 这是由材料原子排列的长程无序性所致. 本综述首先介绍了一些最近出现的新颖和独特的非晶纳米材料的 制备方法. 由以上方法所得到的非晶纳米材料具有轮廓分明、形貌规则等特点, 摆脱了传统非晶材料呈现的无规则状颗粒或者薄膜的 局限. 本文选取了一些有特色的新颖的非晶纳米材料, 来说明现阶段它们在电化学电极材料以及光响应方面的应用原理以及方式. 如 今, 国内外对于非晶纳米材料的研究刚刚起步, 仍然有很大的探索空间. 研究者不断开发和创造出来的科学方法和技术将有利于非晶 研究的快速发展, 进而开发新的应用. 非晶纳米材料的可控制备必将掀起纳米领域研究的新高潮. 